\title{
PREMISAS PARA EL TRATAMIENTO DE LOS GRUPOS EMPRESARIALES Y ADMINISTRADORES DE HECHO EN EL DERECHO CHILENO*
}

\author{
PREMISES FOR THE TREATMENT OF THE CORPORATE GROUPS AND \\ ADMINISTRATORS OF FACT IN THE CHILEAN RIGHT
}

\author{
EdUARdo JeQuier LeHUEDÉ ${ }^{* *}$
}

\begin{abstract}
RESUMEN: La presente investigación apunta a descubrir la naturaleza y fines de los grupos empresariales para, a partir de ahí, definir el concreto estatuto de responsabilidad que debe aplicarse en el derecho chileno a los entes dominantes y a sus administradores de derecho, considerados para tales efectos como administradores de hecho de la sociedad dominada. Se revisan para ello, de manera crítica, las figuras del levantamiento del velo y la atribución de responsabilidad extracontractual por el hecho ajeno, utilizadas por la doctrina y la jurisprudencia en Chile, y se propone en consecuencia la formulación de un nuevo estatuto de responsabilidad, tomando como punto de partida los postulados de la teoría del administrador de hecho en los sistemas comparados.
\end{abstract}

Palabras clave: Administrador de hecho, grupo empresarial, responsabilidad patrimonial, administrador de derecho, administrador oculto, administrador notorio.

\begin{abstract}
This research aims to discover the nature and purpose of the corporate groups in the Chilean law for, from there, define the concrete statute of responsibility that must be applied to the dominant entities and to his administrators in law, considered for such effects as administrators of fact of the dominated company. There are checked for it, in a critical way, the figures of disregard of legal entity and the attribution of extracontractual responsibility by the fact of a third person, used by the doctrine and jurisprudence in Chile, and therefore proposed the formulation of a new statute of responsibility, taking as a starting point for it the postulates of the theory of the fact administrator in the compared systems.
\end{abstract}

Key words: Fact administrator, corporate group, patrimonial responsibility, administrator in law, hidden administrator, notorious administrator.

\section{INTRODUCCIÓN}

A partir de la crisis del sistema financiero del año 1982, la legislación chilena ha venido incorporando una serie de exigencias en materia de inversión, control, grupos empresariales y personas relacionadas, todas orientadas a regular los efectos de la concentración

\footnotetext{
El presente estudio se ha realizado como parte del Proyecto FONDECYT Iniciación año 2012, N¹1121226, titulado "Quiebra e insolvencia en los grupos empresariales. Aproximación hacia supuestos de responsabilidad desde la perspectiva de la teoría del administrador de hecho", del cual el autor es investigador responsable.

${ }^{*}$ Doctor en Derecho, Universidad de Valencia, España. Mg. en Derecho de la Empresa, P. Universidad Católica de Chile. Profesor de Derecho Comercial, Universidad de Los Andes y Universidad Católica del Norte. Correo electrónico: ejequier@uandes.cl
} 
económica y crediticia que originó precisamente la crisis de la banca en aquella época. La Ley No 18.660 por lo mismo (D.O. de 20 de octubre de 1987), agregó el Título XV de la Ley de Mercado de Valores -LMV-, artículos 96 a 102, con el concreto propósito de reconocer la existencia - primero- y de regular los alcances -después- de un fenómeno que si bien venía observándose hace mucho en la práctica societaria chilena y comparada ${ }^{1}$, no había sido abordado aun por el legislador.

Derivado precisamente del fenómeno de las personas y empresas relacionadas, la concentración económica y la conformación de grupos empresariales constituye una consecuencia natural y en cierto modo espontánea de la actividad económica, cuyas manifestaciones más radicales se encuentran ya en los postulados del laissez faire del liberalismo clásico del siglo XIX. Tales principios, atemperados por cierto a través del rol tutelar que el modelo económico neoliberal le asigna al Estado en materia económica, se recogen actualmente en Chile a través de normas constitucionales y legales que, lejos de prohibir la formación de grupos de empresas, apuntan a reconocer su licitud y a revelar desde allí su existencia y composición.

La legislación chilena, junto con reconocer y regular entonces el fenómeno de las personas relacionadas en cuanto vehículo de control indirecto y nutriente -a su turno- de la formación de grupos de sociedades, ha concentrado sus esfuerzos en el perfeccionamiento de los mecanismos de ejercicio del control y en el manejo de la información que producen los grupos empresariales de cara al funcionamiento del mercado de valores. Sin embargo, y a diferencia de lo que ocurre en otros países, en Chile el desarrollo doctrinal, legislativo y jurisprudencial de los grupos empresariales se mantiene aún en un plano incipiente y esencialmente descriptivo, con aspectos de la mayor relevancia que esperan todavía un análisis y tratamiento específico.

Por lo anterior, la presente investigación apunta a desentrañar la naturaleza y fines de los grupos empresariales para, a partir de ahí, dilucidar el concreto estatuto de responsabilidad que le corresponde a los entes dominantes y a sus administradores de derecho, situados en un marco dogmático que presenta matices propios y distintos de los que modelan el régimen general de responsabilidad en una sociedad individualmente considerada. Postulamos, en tal sentido, la necesidad de revisar los criterios de imputación de responsabilidad que se han aplicado en Chile en este ámbito, fundados principalmente en la doctrina del levantamiento del velo y, en ocasiones, en la figura de responsabilidad por el hecho ajeno, lo que ha llevado a forzar sin embargo sus presupuestos para acomodarlos a las particulares características del fenómeno grupal. A partir de los postulados de la teoría del administrador de hecho, en fin, consagrada expresamente en diversos ordenamientos comparados, pretendemos introducirnos en la dinámica propia y característica de los grupos empresariales para definir, en ese preciso contexto, el régimen de responsabilidad que debe aplicarse, lege ferenda, a quienes asumen de manera oculta o tras las sombras el carácter de adminis-

\footnotetext{
1 Al año 2010, conglomerados como "Fiat" o el grupo "Edison", en Italia, superaban las mil sociedades dependientes. En Japón, el 90\% de las sociedades constituidas pertenecen a algún grupo empresarial, mientras que en Alemania, Estados Unidos, Francia y Gran Bretaña el número alcanza al 70\%, al 65\%, al 60\% y al 55\%, respectivamente. Véase Galgano (2012) p. 11.
} 
tradores de los entes agrupados, determinando en la realidad las políticas y directrices de gestión de cada cual en cuanto partícipes del grupo en su totalidad.

\section{ALGUNAS CONSIDERACIONES FUNDAMENTALES SOBRE LOS GRUPOS EMPRESARIALES EN EL DERECHO CHILENO Y COMPARADO}

\subsection{Reconocimiento nORMativo De los GRUpos Empresariales y SU REGULACIÓN EN EL DERECHO CHILENO}

La regulación de los grupos empresariales en el derecho chileno no difiere ontológica y conceptualmente de lo que se observa en el derecho continental europeo y en los sistemas del common law, que precisamente lo han orientado e influenciado. La ley, lejos de prohibir o limitar la conformación de tales grupos, reconoce su existencia como una realidad preexistente y afianzada, legítima y hasta necesaria de cara a la organización jurídica de la mediana y gran empresa moderna, interviniendo únicamente para evitar el abuso de la posición de poder o, como apunta Brunetti ${ }^{2}$, “cuando es necesario para impedir o reprimir cualquier fenómeno degenerativo" 3 .

Lo dicho supone aceptar, por ende, que el sometimiento del interés de las sociedades dominadas o dependientes al interés colectivo del grupo constituye la manifestación más notoria de un fenómeno económico-jurídico originado en la iniciativa empresarial, que por necesario no ha podido ser prohibido ni restringido por el legislador en términos tales que lo hagan impracticable 4 . Dicho de otra forma, el solo reconocimiento de los grupos empresariales como un fenómeno fundado en el ejercicio legítimo de la autonomía de la voluntad y del derecho de propiedad ${ }^{5}$, funcional además a los desafíos de la economía moderna y de los emprendimientos a gran escala, presupone aceptar a su vez la supremacía de ese interés grupal respecto del interés de cada miembro individualmente considerado, en el entendido que la sinergia grupal terminará por compensarlo en un periodo razonable ${ }^{6}$. Cosa distinta son las eventuales consecuencias dañosas que pueda generar la actuación del interés domi-

\footnotetext{
2 BrunetTi (1960) p. 54.

3 Es lo que señaló la Corte Suprema, conociendo de un recurso de reclamación en el marco de la fusión LANTAM:“(...) no debe olvidarse -dice la CS- que los recurrentes mediante la realización del negocio de concentración renuncian al derecho que tienen a desarrollar sus actividades económicas individualmente y seguir compitiendo entre ellas, privilegiando en cambio realizar las actividades en común y eliminar un importante competir actual y potencial. La regla general establecida en el artículo $19 N^{\circ} 21$ de la Constitución Política relativa a la libre iniciativa empresarial cede en la especie ante la limitación del orden público económico, que dice relación con el hecho de que se sobrepone al reconocimiento de los intereses económicos a través del objetivo de prevenir que se cause una lesión al derecho de la libre competencia al fusionarse un agente económico con uno de sus principales competidores y por ende se ponga en peligro la libre elección de los consumidores". Sentencia Corte Suprema (2012) Rol N 9843-2011.

4 Véase Embid Irujo (1986) p. 87.

5 Se trata en efecto de un fenómeno surgido como consecuencia de la creación de la sociedad de capital por acciones, el principio de libre circulación de las mismas y la limitación de responsabilidad de los accionistas, lo que por virtud de la iniciativa empresarial y la autonomía negocial derivó en la formación de estructuras intersocietarias integradas, controladas normalmente a partir del ejercicio del derecho de propiedad que se tiene sobre las mismas acciones.

6 Véase Corporate Group Law for Europe (2000) pp. 265-286. Sobre las compensaciones en los contratos de grupo, regulados por el derecho español, puede consultarse a De Arriba Fernández (2004) p. 269 y ss.
} 
nante en este ámbito, tanto para el interés de los entes dominados cuanto para sus socios o accionistas y acreedores, pues en tales casos el ordenamiento jurídico debe proporcionar herramientas resarcitorias adecuadas a la dinámica del grupo, fundadas en último término -y a falta de regulaciones particulares para los grupos empresariales- en el deber genérico de no causar daño a otro. Sobre esto volveremos más adelante.

En este contexto entonces, al legislador le corresponde objetivar las bases, normas y principios de orden público económico plasmados en la Constitución, que apuntan a resguardar la fe pública y a evitar el abuso de la libertad que la propia Constitución le reconoce a los particulares para formar grupos de sociedades (art. $19 \mathrm{~N}^{\circ} 15$ y $19 \mathrm{~N}^{\circ} 21$ de la Constitución Política de 1980). Para dicho propósito, pues, la ley chilena sobre Mercado de Valores $\left(\mathrm{N}^{\circ} 18.045\right)$ ha optado por garantizar la transparencia en la conformación y funcionamiento de los grupos empresariales -concepto que incluye por cierto a los grupos de sociedades-, revelando su existencia misma y proporcionándole al mercado un flujo permanente de información relevante sobre las entidades del grupo, sus valores y sus operaciones relacionadas ${ }^{7}$. Simultáneamente, la Ley de Sociedades Anónimas -LSA-, N ${ }^{\circ}$ 18.046, se ocupa de reducir los riesgos que pueden generar estas combinaciones empresariales de cara a la buena fe de los accionistas minoritarios -que permanecen extraños al control del dominante- $\mathrm{y}$ de los acreedores de los entes dominados, subordinando en ciertos casos el interés de los propios accionistas ${ }^{8}$ y fijando en otros las bases y requisitos que deben concurrir en toda negociación, operación, acto o contrato entre partes relacionadas?

\subsection{ELEMENTOS CONFIGURADORES DEL GRUPO EMPRESARIAL}

Un primer aspecto a considerar en este punto es la dificultad que plantea el análisis jurídico del fenómeno de los grupos empresariales, integrado por una diversidad de elementos -cada uno con sus matices- que conspiran contra cualquier intento de regulación normativa uniforme.

Desde luego, los grupos empresariales no admiten un único origen y pueden clasificarse por ende en grupos de facto, simples o cualificados (originados en factores de propiedad o participación societaria y caracterizados por su organización unitaria ${ }^{10}$ ), en

\footnotetext{
7 Los grupos empresariales en Chile, reconocidos como tales por la Superintendencia de Valores y Seguros en conformidad al art. 96 de la LMV y a la Circular No 1664 de la misma Superintendencia, de 10 de abril de 2003, pueden consultarse en http://www.svs.cl/sitio/mercados/grupos.php.

8 Así ocurre por ejemplo con el art. 29 de la LSA, que ante la quiebra de la sociedad subordina los créditos de sus accionistas, derivados de una disminución de capital, a los créditos de los acreedores sociales, haciendo aplicables además las causales objetivas de inoponibilidad concursal del art. 76 de la Ley de Quiebras respecto de los pagos ya efectuados a dichos accionistas.

9 En este sentido, el Título XVI de la LSA, introducido por la Ley N 20.382 (D.O. de 20 de octubre de 2009), fijó un estatuto de mínimos para resguardar la fe pública y el interés de los accionistas minoritarios y acreedores en general, sin llegar a prohibir una determinada especie o categoría de actos, contratos, negociaciones u operaciones entre partes relacionadas. La ley, por el contrario, optó por un criterio de validación genérica de los mismos, sin perjuicio de las acciones directas o derivativas de reembolso que la misma normativa contempla.

10 Grupo de facto simple es aquel en que las sociedades controladas mantienen cierto margen de autonomía frente a la controladora, mientras que los cualificados son aquellos en que el controlador "actúa sin límites de ningún tipo por el resto de los socios”. Girgado Perandones (2002) pp. 123 y 124.
} 
grupos de colaboración subjetiva (o de uniones personales, como las califica Brunetti ${ }^{11}$ ) y en grupos de carácter convencional, derivados de relaciones contractuales entre sociedades con objetivos comunes, incluso de carácter cooperativo. Tampoco su conformación estructural es unívoca, pues, dependiendo de las necesidades y objetivos que cada cual, los grupos empresariales pueden integrarse en forma vertical (esto es, como grupo de empresas subordinadas ${ }^{12}$ o piramidales ${ }^{13}$ ), horizontal (de empresas coordinadas o de estructura paritaria ${ }^{14}$ ) o radial, en donde una misma sociedad es controladora de otras tantas, simultáneamente y de manera directa ${ }^{15}$.

11 Se trata concretamente de uniones entre empresas que comparten normalmente a sus directivos principales. BRUnetTi (1960) p. 55. Al tenor de los arts. 97 y 98 de la LMV chilena, nos parece además que en esta categoría quedan comprendidos aquellos grupos formados a partir de acuerdos de actuación conjunta, originados precisamente en un vínculo de cooperación entre los partícipes de los acuerdos respectivos, destinados a obtener el control.

12 En este caso existe una relación de dependencia o dominación entre las sociedades del grupo, lo que deriva en una voluntad unitaria del grupo marcada por las políticas empresariales del dominador. Dicha subordinación, a su vez, puede tener su origen en el control obtenido mediante la participación accionaria (como ocurre en la gran mayoría de los casos); por un acuerdo entre sociedades que conservan su autonomía, compartiendo una estrategia económica común con miras a repartirse los beneficios (como ocurre por ejemplo con los carteles); por la intervención de los administradores o directores de una sociedad en el órgano administrativo de otra (como ocurre muchas veces con los bancos, cuyos directores intervienen en los directorios de las grandes empresas deudoras), por nombrar las principales. Sobre este punto puede consultarse la obra de GARRANI (1939) p. 366 y ss. y pp. 376 y ss.; BRUNETTI (1960) pp. 56 y 57.

13 Los grupos piramidales, por oposición a las estructuras radiales, se describen como una cadena más o menos larga de control, que usa varios holdings; o en palabras de la Comisión de las Comunidades Europeas, son "cadenas de sociedades de cartera cuyo control final se basa en una inversión total modesta gracias a un recurso muy amplio a los accionistas minoritarios". Comunicación de la Comisión al Consejo al Parlamento Europeo. Modernización del Derecho de sociedades y mejora de la gobernanza empresarial en la Unión Europea - Un plan para avanzar" (2003) p. 22. En la estructura piramidal, común en el ámbito financiero. Véase Vivante (1935) p. 18; Vivante (1931) p. 150 y ss., los accionistas de control pueden llegar a dominar la cadena entera por la vía de controlar cada empresa o nivel de la cadena, ya sea por mayorías o manejando el interés minoritario, lo que se consigue además con una pequeña inversión total. Véase Report of the High Level Group of Company Law Experts on a Modern Regulatory Framework for Company Law in Europe (2004) p. 98. Así por ejemplo, en una estructura con un accionista y que detenta el $25 \%$ del capital de la sociedad A, pero que la controla no obstante por un acuerdo de voto en Junta; sociedad esta que a su vez es dueña del $51 \%$ de la sociedad B, la que a su turno es controladora de la sociedad C y esta, por su parte, lo es de la sociedad D, es perfectamente posible que el accionista $Y$ termine por controlar a la sociedad D con una participación cercana al $3 \%$ del capital de esta última.

${ }^{14}$ Se trata de aquel grupo societario en donde no existe una relación de dominación o dependencia de unas sociedades respecto de otras integradas en el mismo grupo Miguens (2006) p. 55 y ss.; Galgano (2012) p. 256. En estos grupos, por ende, lo relevante es la dirección unitaria, sin necesidad que concurra además el elemento de subordinación recién mencionado. La figura se encuentra especialmente contemplada en la ley alemana sobre sociedades anónimas (Aktiengesetz-AktG-), en donde no hay grupo por dominación únicamente, bastando la concurrencia del elemento de dirección suprasocietaria o común. Tal solución es criticada sin embargo por alguna doctrina, que considera que no puede concebirse al grupo sin una unidad económica que, a su turno, solo será posible si existe un vínculo de relación societaria con dependencia. Por todos BIANCHI (1984) p.989 y ss.; en igual sentido EMBID (1986). No compartimos esta última tesis, ni es tampoco la que sigue el legislador chileno al definir y caracterizar a los grupos empresariales. La dirección unitaria, en efecto, puede generarse y permanecer estable en el tiempo por vías que no necesariamente deben coincidir con la figura de las personas relacionadas por propiedad, como ocurre por ejemplo con las vinculaciones de carácter subjetivo (administración compartida) o incluso contractual (compromiso de activos y/o relaciones crediticias de especial entidad).

15 Véase Vásquez Palma (2013) p. 155. 
Por otro lado, debe tenerse en cuenta que la condición de accionista mayoritario, aunque sea de control, no involucra siempre y necesariamente la incorporación de la sociedad dominada al grupo empresarial del primero ${ }^{16}$. Dicho de otra forma, para que exista un grupo no basta con tener el poder suficiente para controlar, sino que ese poder debe ser ejercido con miras a obtener la dirección unitaria del grupo en su conjunto. El grupo, en fin, no es sinónimo de control actual o potencial sino la objetivación de un fenómeno más amplio y complejo, integrado por elementos que, aunque difíciles de aprehender ${ }^{17}$, son reconocidos como tales por el legislador y la doctrina nacional ${ }^{18}$ y comparada. Nos referimos, en concreto, a la existencia de una voluntad y estrategia de dirección suprasocietaria, que se revela a través de dos vertientes distintas según veremos a continuación: la influencia dominante que ejerce el controlador y a la dirección unitaria orientada hacia un objetivo superior.

\subsubsection{Influencia dominante (o relación de dependencia)}

Tratándose de los grupos por subordinación -como es el caso de la gran mayoría de grupos empresariales en Chile-, la influencia dominante consiste en la dependencia o subordinación de unas sociedades - las controladas- respecto de otra -la dominante- que define e impone la voluntad de todo el grupo, ya sea directamente o de manera indirecta.

El art. 97 de la LMV chilena, sin definir la figura del control en cuanto tal (opción acertada por cierto), se refiere a este elemento al precisar quiénes son considerados controladores, fijando para tal efecto los factores alternativos que llevan a presumir iuris et de iure dicho control ("Es controlador...")19. Junto a ellos sin embargo, y cualquiera sea el que se configure en cada caso (mayoría de votos en Juntas o Asambleas, mayoría de administradores o influencia decisiva ex art. 99), la ley contempla otros dos que nos parecen relevantes, uno expreso y otro implícito:

a) En primer término (factor explícito), la LMV exige que el controlador participe en la propiedad del controlado (art. 97 inc. $1^{\circ}$ ), excluyendo por ende las demás formas de subordinación no participativas a que nos hemos referido supra.

b) Un segundo factor (implícito), distintivo siempre de la posición de dominio, radica en que el socio o accionista mayoritario o controlador debe actuar necesariamente como empresario, esto es, desarrollando una conducta que va más allá de la mera administración ordinaria de un paquete de acciones.

Para estos efectos entonces, el accionista particular será considerado empresario solo si es titular directo o indirecto de participaciones en dos o más empresas y actúa, al menos en una de ellas, "de manera correspondiente a la que utilizaría un empresario" ${ }^{20}$, lo que lo

\footnotetext{
16 Domínguez Ruiz De Huidobro (2002) p. 1302 y 1303.

17 Girgado Perandones (2001) pp. 202 y 203.

18 Puga Vial (2011) pp. 648 y 649.

${ }^{19}$ La norma citada sigue muy de cerca en esta parte a la Séptima Directiva de Derecho de sociedades, de la Comisión de las Comunidades Europeas, № 83/349/CCE, de 13 de junio de 1983 (D.O. L 193, de 18 de julio de 1983, pp. 1-17).

20 Duque Domínguez (1987) p. 35.
} 
distingue precisamente del socio o accionista mayoritario/potencial controlador. En otros términos, y por poner un ejemplo, no basta con el manejo de determinados paquetes accionarios -incluso mayoritarios- si al mismo tiempo el titular respectivo no ejerce una influencia dominante en las sociedades controladas, con miras a obtener por esa precisa vía la unidad de dirección que termina por definir al grupo como tal2 ${ }^{21}$.

Este elemento, si bien presenta un componente subjetivo que desincentiva cualquier intento de definición normativa, se objetiva a través de actuaciones concretas $-\mathrm{o}$ al menos potencialmente ejecutables ${ }^{22}$ - que el legislador considera indiciarias del ánimo empresarial autónomo ${ }^{23}$ del accionista de cara al funcionamiento interno de la sociedad controlada, que por su reiteración resultan además perfectamente reconocibles. Así ocurre, por ejemplo, con el ejercicio habitual del derecho a voto en la Junta de Accionistas de la sociedad dominada o dependiente, o con la injerencia y manejo del órgano de administración en general, siempre con miras a definir e imponer los fines, políticas o lineamientos unitarios de organización interna y de planificación estratégica, empresarial y financiera del grupo ${ }^{24}$.

\subsubsection{Política coordinada de dirección unitaria}

Cualquiera que sea la naturaleza o estructura del grupo, su condición de tal estará definida siempre y necesariamente por la existencia de una misma y única voluntad de dirección, diseñada con miras a favorecer el interés del grupo sin respecto al número de entidades integrantes o a la posición que cada cual ocupe en dicha estructura.

El solo control, como se dijo supra, no es elemento suficiente en este sentido; y si bien concurre en el común de los casos, lo concreto es que solo estaremos en presencia de un grupo cuando una pluralidad de sociedades es reconducida al carácter de un ente económico único, por la dirección también unitaria que una de ellas ejerce sobre las demás. El control en cambio, como apunta Montalenti ${ }^{25}$, "consiste en el ejercicio de los poderes de nombramiento de los administradores y, en general, de los poderes organizativos (modificaciones estatutarias, en particular operaciones de reorganización societaria: fusiones, escisiones, etcétera.), elecciones de financiación de la empresa, aumento de capital, etc.”, por lo que si bien puede concurrir en la gran mayoría de los casos, no es sinónimo ni indiciario per se del grupo empresarial.

La LMV se refiere a este aspecto en su art. 96 , inc. $1^{\circ}$, al señalar que habrá grupo empresarial cuando "la actuación económica y financiera de sus integrantes está guiada por los intereses comunes del grupo o subordinada a estos (...)". La norma entonces, si bien no habla

${ }^{21}$ El mero control -dice DuQUE-, la mera dependencia, "tiene que conducir a una situación más cualificada que es la constituida por la unidad de dirección”. Duque Domínguez (1987) p. 32.

22 No es necesario, para que exista influencia dominante y por ende dependencia intersocietaria, que los actos y conductas que la exteriorizan se ejecuten efectivamente. Como apunta DE Arriba, fundándose en el texto del art. 87 de la anterior LSA española, "tiene que existir un poder de dominio sobre otra sociedad, independientemente de que ese poder se utilice o no para interferir en la vida social de esa otra sociedad”. DE ArRIBA (2004) pp. 118 y 119.

23 La influencia dominante es autónoma o estable cuando su ejercicio depende de la sola voluntad, poderes o facultades del accionista titular, y no de terceros. De Arriba (2004) p. 120).

24 Véase Massaguer Fuentes (1989) p. 292.

25 Montalenti (2007) p. 320. 
de dirección unitaria o coordinada, sí se refiere a la actuación o actividad ${ }^{26}$ del grupo y de cada uno de sus integrantes, entendiéndose por tal -para estos efectos- la realización sistemática y constante de una pluralidad de actos de dirección teleológicamente orientados, aptos para influir en la gestión de las empresas miembros de cara a la obtención de un propósito que se estima superior ${ }^{27}$. Se trata, en fin, del diseño e implementación de estrategias y políticas de gestión encaminadas a la obtención de objetivos de orden económico, financiero, comercial e incluso de pura consolidación tributaria ${ }^{28}$, lo que se traduce finalmente en que "(...) las sociedades controladas son usadas como instrumento de la política empresarial de grupo, a través de una concentración por el controlador de funciones y estrategias inherentes la gestión de las controladas"29.

\section{LA FIGURA DEL ADMINISTRADOR DE HECHO EN LOS GRUPOS EMPRESARIALES. ESTADO DE LA CUESTIÓN Y PROPUESTAS EN EL DERECHO CHILENO DE SOCIEDADES}

Hemos dicho supra que una de las características esenciales del grupo empresarial radica en el carácter unitario de su dirección y en la existencia, por lo mismo, de una voluntad común superadora de los límites de la personalidad jurídica y del interés de cada uno de los miembros que lo integran, sus accionistas y administradores.

$\mathrm{Al}$ respecto, y considerando que en el ámbito del Derecho comercial chileno no existe una aproximación normativa al grupo empresarial en cuanto titular unificado de los efectos jurídicos que genera la actividad de cada miembro, nos parece indispensable delimitar el ámbito de responsabilidad de los administradores que han intervenido en operaciones eventualmente lesivas para el interés de los accionistas minoritarios -ajenos por ende al grupo- y de los acreedores en general, incluida la quiebra de alguno de dichos integrantes. Todavía más, y a diferencia de lo que ocurre por ejemplo en el Derecho laboral ${ }^{30}$ o en el

\footnotetext{
${ }^{26}$ El concepto de "actividad", para describir el elemento de dirección u organización coordinada y unitaria, es utilizado actualmente -entre otros- por el C.C. italiano, art. 2497 y ss., según el texto introducido por el Decreto Legislativo $\mathrm{N}^{\circ} 17$, del año 2003.

27 En el ámbito del Derecho común europeo, la CCE se ha encargado de precisar en diversas ocasiones las principales manifestaciones que presenta este elemento en particular, tales como el propio control, la administración común o compartida, la actuación unitaria en ámbitos sensibles de su giro o actividad y, en fin, la imagen unificada que se exhibe en los mercados que les son relevantes (por todos, véase la Decisión CCE, de 16 de julio de 2008, relativa a la medida de ayuda ejecutada por Francia en favor del grupo IFP, p. 28).

28 Para Gerum, la popularidad relativa de acuerdos corporativos en Alemania puede ser atribuida a objetivos de planificación tributaria. Así, una mayoría de alrededor del $70 \%$ de los grupos sujetos a la ley de Codeterminación de 1976 (como los grandes grupos), se encuentran organizados sobre esta base, más fáctica que contractual. Gerum (1998) p. 10.

29 Es la descripción dada en el derecho italiano por la Circolare Assonime No 44/2006, sobre "Dirección y coordinación de sociedad. Perfiles de organización y responsabilidad del fenómeno del grupo” (2006) pp. 1098 y 1099. Traducción libre del autor. Sobre la dirección unitaria puede consultarse la obra de DE ARRIBA (2004) p. 197 y ss.

30 Por la vía de aplicar el denominado principio de primacía de la realidad, diversas sentencias han hecho extensiva la responsabilidad laboral de las empresas dominadas a las dominantes o controladoras, considerándolas en su conjunto dentro del concepto legal de empresa del art. 3 del Código del Trabajo (por todas, Sentencia C. Suprema, de 28 de septiembre de 2005, Rol No 833-2004). Sobre el concepto y tratamiento de los grupos de
} 
Derecho tributario $^{31}$, en Chile no existe tampoco una elaboración jurisprudencial que permita construir un estatuto diferenciado y definido de responsabilidad en estos casos, cuyos extremos vengan definidos precisamente por la existencia y el reconocimiento de un interés unitario o aglutinador de la dinámica grupal, en su concepción de empresa plurisocietaria.

En este esquema, entonces, la opción por un determinado sistema de responsabilidad constituye una tarea especialmente compleja, con extremos que van desde aplicar simplemente el régimen común sobre conflictos de intereses y responsabilidad en su perspectiva intrasocietaria (cosa que en este caso nos parece impracticable o notoriamente insuficiente al menos ${ }^{32}$ ), hasta considerar que la responsabilidad patrimonial debe ser una misma y única para todo el grupo. O planteado de otra forma: Así como el grupo está regido por y se nutre de una sola voluntad de dirección, así también debería ser tratado, mutatis mutandi, en lo que concierne a su responsabilidad como ente económico único por los perjuicios derivados de la actuación de su interés suprasocietario, inserto no obstante en una estructura formalmente pluriempresarial.

Entroncamos de esta forma con la figura del administrador de hecho, que comenzamos a explorar.

\subsection{UNA PRIMERA DISTINCIÓN NECESARIA: INTERÉS SOCIAL, INTERÉS DE LOS}

\section{ACCIONISTAS, INTERÉS DE LOS ADMINISTRADORES E INTERÉS DEL GRUPO}

Uno de los aspectos de especial complejidad que presenta el Derecho de sociedades, cuyo análisis presupone incluso - para algunos autores al menos- la incorporación de elementos que traspasan los límites de lo estrictamente jurídico, consiste en definir y a su vez en delimitar los diversos intereses que confluyen en el funcionamiento de una sociedad, principalmente de capital. No es nuestro propósito, por lo mismo, el adentrarnos aquí en un estudio pormenorizado de los distintos intereses antes mencionados, materia esencialmente compleja y a la que nos hemos referido ya en otra oportunidad ${ }^{33}$. El concepto de

empresas en el Derecho laboral chileno, puede consultarse la obra de RojAs Miño y AylWIn Chiorrini (2007) en especial pp. 65 y ss.

31 Algunas normas legales de carácter tributario se refieren directa o indirectamente al fenómeno de los grupos empresariales, regulando por ejemplo la situación de ciertas personas relacionadas a una sociedad de cara al régimen de tributación aplicable (art. 20, $\mathrm{N}^{\circ} 1$, letra b, inc. final, del D.L. 824, sobre Impuesto a la Renta). La jurisprudencia judicial y administrativa, además, se ha pronunciado en reiteradas ocasiones sobre la situación tributaria de las personas relacionadas, entre las que se incluyen por cierto - sin ser lo mismo necesariamente- a los grupos empresariales (por todas, Sentencia C. Suprema, de 13 de septiembre de 2012, Rol No 3830-2010. Id. LegalPublishing CL/JUR/2056/2012; 62723). Sin embargo, es en el art. 99 del Código Tributario en donde la ley se refiere implícitamente a la figura del administrador de hecho o del administrador oculto o en las sombras, al referirse a quienes "hagan las veces" de administradores o representantes de personas jurídicas contribuyentes.

32 En el mismo sentido se plantea el Reporte de Bruselas de 4 de noviembre de 2004, ya mencionado ("Report of the High Level Group of Company Law Experts on a Modern Regulatory Framework for Company Law in Europe (2004) p. 96 y ss.

33 El concepto de interés social es especialmente complejo y variable, pues depende de la noción jurídicoeconómica que se tenga del interés de los accionistas y de la naturaleza y fines de las sociedades de capital, tomando como base para ello los extremos contractualistas-institucionalistas desarrollados por la doctrina comparada. Sobre este aspecto puede consultarse entre otros a SÁNCHEZ-CALERo (2002) pp. 1653-1663; RoIMISER DE (1979) p. 2 y ss.; JeQuier (2013); AlCAlde (2007) en especial p. 31 y ss.; SÁnchez, Ruiz (2000) p. 64. 
interés social, en efecto, entronca y se relaciona necesariamente con aquellos principios que cada ordenamiento se ha dado para definir la naturaleza y la función de la sociedad mercantil, según el tipo societario de que se trate. Tales principios, que la doctrina califica como configuradores del tipo social, se funden en cuanto tales con la noción de orden público, asumiendo así la fisonomía que este les imprime como baremo valórico-normativo que encarna el interés preponderante en un momento determinado.

Para los efectos de esta investigación, con todo, resulta necesario referirnos a una supraesfera de interés autónomo, como es el interés del grupo, lo que presupone revisar brevemente al menos los diversos intereses que interactúan en el funcionamiento de una sociedad, principalmente de capital. Tal revista permitirá completar un panorama especialmente diversificado de intereses concurrentes -aunque no necesariamente coincidentes-, cuya configuración depende de una serie de factores a considerar en el análisis de los grupos empresariales y del esquema de responsabilidad aplicable a los mismos.

Para definir la responsabilidad derivada de los actos lesivos que genera la dinámica grupal, en efecto, causados ya sea a las sociedades dominadas que lo integran, a sus acreedores o a los accionistas minoritarios en general -que por lo mismo permanecen extramuros de la voluntad unitaria del grupo-, necesariamente deben tenerse en cuenta los diversos intereses afectados - por un lado- y aquellos otros que por contrapartida han resultado beneficiados por el actuar del administrador de hecho, sea este la sociedad controladora como tal (cuando el interés grupal lesivo surge de y se encuentra en consonancia con el interés manifestado en la junta y en el órgano de administración, según sus respectivos ámbitos competenciales) o los administradores de la dominante en los supuestos de propiedad difusa antes mencionado .

\subsubsection{Interés social, interés de los accionistas e interés de los administradores.}

En Chile la LSA, reconociendo precisamente la coexistencia de intereses distintos y su eventual colisión al interior de la sociedad, declara expresamente que "Los accionistas deben ejercer sus derechos sociales respetando los de la sociedad y los de los demás accionistas" (art. 30). Es la propia ley por ende, en la disposición recién citada y en aquellas que establecen los deberes fiduciarios de los directores y gerentes de la sociedad anónima (arts. 41, 42 y 50 de la LSA, entre otros), la que hace una clara separación entre los derechos del accionista y el interés de la sociedad en cuanto tal, reconociendo por ende su existencia como fenómenos distintos. Así también lo hace la LMV en su art. 10 inc. $3^{\circ}$, al tratar sobre el deber de información y particularmente sobre la información reservada en el mercado de valores.

Advirtamos desde ya, sin embargo, que la diversidad del espectro tipológico de la sociedad de capital, ya sea anónima -cerrada, especial, abierta o cotizada- o por acciones, hace imposible abordar de manera unitaria el estudio de los intereses que en ella coexisten; esto es, de una forma tal que permita obtener conclusiones generales y extrapolables por ende a cada tipo societario por igual.

En la sociedad anónima abierta, por ejemplo, el fenómeno del accionariado se compone de una multiplicidad de aspectos distintos y, además, por sujetos con características e intereses muy dispares entre sí, como el pequeño inversionista que ninguna injerencia e interés tiene en la administración de la sociedad; o el gran accionista con poder suficiente 
para controlarla tanto en la Junta de Accionistas cuanto en el Directorio; o el accionista empresario, que sin llegar a controlar necesariamente la sociedad participa activamente en su administración; o, en fin, el inversionista institucional que asume una actitud muchas veces pasiva de cara a la administración. En las grandes sociedades cotizadas, además, los accionistas minoritarios deben asumir el riesgo latente de que terceros adquieran la mayoría necesaria para tomar el control de la sociedad, en cualquier momento, pudiendo abusar eventualmente de él por efecto del sistema de mayorías que establece la ley. Por contrapartida, la estructura política de estas sociedades determina que al interior de ellas el interés que tienen los accionistas que detentan su control, movidos por un criterio empresarial y con el propósito de obtener una valorización del capital mediante el manejo del poder, no es ni puede ser el mismo que tienen a su vez aquellos accionistas que conforman el grupo disperso del accionariado, cuyo único propósito es obtener una rentabilidad a corto o mediano plazo sin tener, por lo mismo, interés alguno en la administración y el control de la sociedad. Todos aportan capital a la sociedad, sin duda; pero mientras los primeros lo hacen con el propósito de dirigir el curso de los negocios y actividades sociales, los restantes solo miran por un interés patrimonial y hasta especulativo. Por ende, en estas sociedades los conflictos de intereses se producirán principalmente entre los accionistas y los administradores de derecho o de hecho, dependiendo del grado de atomización del accionariado, y en menor medida entre los accionistas empresarios y los accionistas inversores.

El interés de los accionistas de una sociedad anónima cerrada o de carácter familiar, en cambio, cuya conformación accionaria evoca muchas veces rasgos subjetivos o intencionales que son propios de la sociedad personalista , será probablemente -aunque no necesariamente- más homogéneo e internamente compatible que aquel que puedan tener a su vez los accionistas de una sociedad cotizada, caracterizada por la posibilidad continua del libre cambio de socios. En este subtipo societario, por ende, el elemento personal tiene especial relevancia, siendo comunes por lo mismo los pactos de accionistas -estatutarios o paraestatutarios- destinados a limitar la libre transmisibilidad de las acciones a terceros ajenos al núcleo subjetivo fundacional, que conserva por lo mismo la primera opción para adquirirlas y preservar por esa vía la solidaridad de intereses. Más que una sociedad intuitu rei, este tipo societario se confunde entonces con las sociedades intuitu personae o, como señalaba ya Manara ${ }^{34}$ a principios del siglo pasado, "en este caso la sociedad anónima sería una verdadera y propia sociedad de personas", cuyos accionistas - mayoritarios o no- mantienen una equivalencia de incentivos en el ejercicio de sus derechos políticos y administrativos, que se refleja en un equilibrio de poderes entre la junta como órgano de gobierno y el directorio como órgano de administración. En consecuencia, y a diferencia de lo que ocurre en las abiertas y cotizadas, en estas sociedades -y en los grupos con tales características- los conflictos de intereses se generarán normalmente entre los accionistas mayoritarios y los minoritarios, y en menor medida entre accionistas y administradores.

\footnotetext{
34 Manara (1902) p. 590. En el mismo sentido se pronuncia Musso, para quien en ciertos casos la sociedad de capital puede no diferir de la sociedad de personas, por cuanto el intuitus personae puede resultar determinante para sus socios. Musso (1996) p.3.
} 


\subsubsection{Interés del grupo}

Por otra parte, aunque vinculado con lo anterior, el interés del grupo se traduce en la búsqueda del máximo beneficio y la mayor rentabilidad para todos los integrantes del grupo en su conjunto, lo que no descarta que en el camino pueda generarse un perjuicio para el interés particular de alguno de ellos. Su sola primacía eventual respecto del interés particular de las sociedades agrupadas -incluida la matriz o controladora ${ }^{35}$-, por lo mismo, presupone una disociación conceptual entre ambas esferas de interés concurrente que el ordenamiento jurídico, según ya se explicó, acepta como una consecuencia legítima de la subordinación grupal.

En Chile, y a diferencia de lo que ocurre en aquellos sistemas -como el español ${ }^{36}$ que no reconocen explícitamente su existencia, el interés del grupo tiene expresa consagración en el art. 96 de la $\mathrm{LMV}^{37}$, que se refiere en concreto a los "intereses comunes del grupo" como elemento rector de la actividad económica y financiera de todos los integrantes del mismo. Aparte de tal mención, sin embargo, la norma no da mayores orientaciones conceptuales o de contenido en torno al significado de la señalada expresión, lo que plantea por ende la necesidad de intentar una aproximación a la misma desde la perspectiva contractualista del derecho chileno de sociedades ${ }^{38}$.

Algunos ordenamientos, de raigambre esencialmente institucionalista como el alemán, identifican el interés del grupo con el interés de la matriz y/o con el interés de las demás sociedades del grupo ${ }^{39}$. En tales casos, por ende, la instrucción perjudicial dada a una filial se ajustará a la consecución del interés grupal en la medida que favorezca el interés de la matriz o de cualquier otra sociedad miembro. Así ocurriría v.gr., con el traspaso de opor-

\footnotetext{
35 El interés y el actuar de la sociedad matriz debe estar marcado por el interés del grupo, sin que pueda apartarse de este último por la vía de instrumentalizar en su beneficio exclusivo la relación de subordinación que describe la estructura grupal. En igual sentido De Arriba (2004) p. 215; Miguens (2006) p. 54.

36 El art. 18 de la Ley española sobre Sociedades de Capital (RDL 1/2010, de 2 de julio) se remite al art. 42 del Código de Comercio para determinar cuándo existe un grupo de sociedades. Ninguna mención se hace sin embargo, en ambos cuerpos legales, al interés del grupo.

37 Esta opción es criticada por alguna doctrina, que entiende que no procede reconocer legalmente la existencia de un interés de grupo si se considera que este, en cuanto tal, carece de personalidad jurídica y, por ende, no puede ser considerado como sujeto de imputación para estos efectos. Véase MöHring (1992) p. 27.

38 En el derecho chileno, la sociedad se define como un contrato surgido de la voluntad de dos o más personas que consienten en poner algo en común, con miras a repartirse los beneficios que de ello provengan (art. 2053 del CC). Por lo anterior, y atendido el contexto histórico en el que se inserta la dictación del CC chileno, la inspiración contractualista de las normas que regulan la sociedad no merece duda. El mismo código, por lo demás, reconoce explícitamente en su art. 2112 la existencia de unos “intereses sociales” que, en determinadas circunstancias, pueden coexistir con el interés individual de los socios, lo que debe interpretarse en consecuencia a la luz de la concepción contractualista que inspiró al legislador de la época según se acaba de explicar. Tal conclusión resulta reforzada incluso por lo dispuesto en el art. 2091 del CC, que asimila precisamente el interés social con el interés común de los socios.

$39 \mathrm{El}$ art. 308.1. de la Aktiengesetz $-A k t G$-, señala: "Vigente un contrato de dominación, la empresa dominante tiene derecho a impartir instrucciones a la Dirección de la sociedad en lo relativo a la administración de la misma. Si el contrato no establece otra cosa, se pueden impartir, también, instrucciones perjudiciales para la sociedad, cuando sirvan a los intereses de la empresa dominante o de las empresas unidas en grupo con ella y con la sociedad". (Trad. de Embid (2010)). Muy similar es el caso de Portugal, art. 503.2 del Codigo das Sociedades Comerciais. Véase DE ArribA (2004) p.217 y ss.
} 
tunidades de negocios de la primera a alguna de estas últimas; o con la fijación de precios especiales de los productos de la filial, para favorecer su compra a menor costo de mercado por parte de la matriz u otra de las agrupadas.

En el caso chileno, en cambio, la asimilación del interés del grupo al interés común de las demás sociedades integrantes del mismo nos parece coincidente con la noción contractualista de la sociedad y del interés social, que rechaza precisamente -al menos en términos generales- la existencia de un interés superior y distinto al de los socios ${ }^{40}$. El interés social se identifica así con el interés común -que no individual- de estos últimos de cara a la obtención, a través de la actividad social, del máximo beneficio posible sin consideración alguna a cualquier otro interés extrasocietario ${ }^{41}$, lo que resulta perfectamente extrapolable a los grupos empresariales. O dicho de otra forma: así como en el plano intrasocietario el interés común de los socios o accionistas no es radicalmente distinto al de la sociedad, el interés del grupo y los intereses comunes de la agrupadas tampoco pueden ser - mutatis mutandi- sustancialmente incompatibles entre sí $^{142}$.

40 Debe advertirse que dentro de la tesis contractualista pueden encontrarse distintas opiniones en torno al concepto de interés social, las que pueden agruparse entre quienes lo identifican con la sumatoria del interés individual de los accionistas fundadores únicamente; los que consideran también el interés de los accionistas que se incorporan posteriormente a la sociedad; y los que entienden el interés social como un reflejo del interés de la mayoría manifestada en Junta.

A su vez, tampoco existe uniformidad dentro de esta doctrina al momento de definir la concreta función que debe cumplir el "interés social". En este sentido, algunos autores entienden que tanto la actuación de los administradores cuanto la de los socios debe estar orientada, siempre y en todo caso, a la consecución y actuación del interés de la sociedad. Como advierte precisamente SÁNCHEZ, se produce en estos casos una suerte de "funcionalización" del voto, que deja de ser un derecho conferido al socio en su propio interés para transformarse, en cambio, en una "potestad o poder-función que deberá ejercitar en interés común”, lo que se asemeja por ende a los postulados de la tesis institucionalista SÁnchez RuIz (2000) pág. 62. Jaeger en cambio, partiendo también de una postura contractualista del interés social, sostiene que la mayoría de los autores lo consideran solo como un límite genérico al que los socios deben atender en el ejercicio de sus derechos, principalmente el de voto, los que en todo caso se le confieren por la ley para la satisfacción de sus propios intereses en la sociedad. Cfr. JAEger (1964) Cap. III.

41 Para Preite, ni siquiera es necesario que el interés tenga un carácter común a todos los socios. Partidario de una concepción contractualista amplia del interés social en el derecho italiano, para este autor los intereses sociales pueden clasificarse en "típicos" y "atípicos". Los intereses "típicos" son aquellos que se encuentran tutelados de modo expreso por concretas normas jurídicas, dentro de los que se puede distinguir: a) el interés por la maximización del beneficio social (arts. 2392 y 2393 del Codice Civile italiano); b) el interés por la percepción de dividendos (art. 2433 del mismo Codice); c) el interés por mantener el grado de influencia en la estructura del capital ante un aumento del mismo (art. 2441 del Codice); d) el interés por intervenir en la determinación del grado de riesgo a que debe someterse la actividad social, a través de la regulación del derecho de retiro o separación del accionista (arts. 147, 149 y 225 de la LSA italiana); e) el interés en la determinación del grado de transmisibilidad de la participación social a través de la clasificación de las acciones en nominativas y al portador, y la posibilidad de establecer limitaciones estatutarias en tal sentido (art. 2355 del Codice y art. 146 de la LSA, respectivamente); f) el interés en la determinación de la duración de la propia inversión a través de las normas sobre disolución de la sociedad anónima (art. 260.1 de la LSA) y; g) el interés en el manejo de la gestión administrativa. Los intereses "atípicos", por su parte, son aquellos que si bien no se encuentran reconocidos y protegidos expresamente por una norma legal, pueden deducirse de y tutelarse por la aplicación de los principios generales que informan el Derecho de sociedades en general y de las sociedades anónimas en particular. PreITE (1992), pp. 24 y ss.

42 En igual sentido GiRGADO, justificando la necesidad de una gestión coordinada de actuación entre los administradores de la matriz y sus filiales. La pertenencia al grupo - dice- también debe aportar beneficios a la filial. Girgado (2002) p. 203. 
En este contexto dogmático, en fin, el interés común se presenta como un elemento distinto del interés de cada accionista o de cada uno de los miembros del grupo ${ }^{43}$, individualmente considerados; y distinto también de la simple sumatoria de esos intereses particulares ${ }^{44}$. Dicho interés común, con todo, no debe confundirse con la existencia de un interés de la sociedad o del grupo que sea sustancialmente distinto del interés de cada accionista, pues, como señala Sánchez ${ }^{45}$, "la distinción entre interés común o del grupo social y el interés individual del socio 'uti socio' se aproxima, más bien, al reconocimiento de un centro autónomo de imputación, referido al grupo conformado por el conjunto de los socios. (...) no se establece a priori una superioridad general del interés común o social, sino que se trata únicamente de diferenciar esferas o conjuntos de intereses (...)”. Dicho de otra forma, en su vertiente contractualista el interés común se configura con base en el interés legítimo que es compartido por todos los socios o miembros en su condición de tales y con independencia de las particulares motivaciones de cada cual, sin que constituya por ende una categoría axiológica sustancialmente distinta y superior. De lo contrario, la línea divisoria entre la orientación contractualista restringida del interés social y la tendencia institucionalista del mismo interés se tornaría en extremo incierta y difusa, lo que no encuentra sin embargo sustento en el derecho positivo chileno.

En síntesis, y considerando que en el Derecho chileno de sociedades la titularidad de los mencionados intereses se atribuye en último término a los socios y no a terceros ajenos a la relación societaria (trabajadores, consumidores, etc.), la distinción entre interés social/ interés del socio e interés grupal/interés de las agrupadas no implica reconocer la existencia de un interés de la sociedad (relación intrasocietaria) o del grupo (vinculación suprasocietaria) que sea superior y distinto per se al interés común de los socios o miembros del grupo, respectivamente, pues estos deben ser esencialmente compatibles entre sí de cara a los elementos configuradores de la sociedad. En consecuencia, nos parece que la instrucción dada por la controladora a la(s) sociedad(es) controlada(s), que sea contraria al interés común del grupo (refundido normalmente en una expectativa de maximización de utilidades), constituye un ejercicio ilegítimo del poder de dominación; y viceversa, si la instrucción causa un perjuicio a alguna de las filiales, pero se encuentra en consonancia con el referido interés común, deberá primar este último en cuanto ejercicio legítimo de la dinámica grupal.

\footnotetext{
43 El Tribunal Supremo español ha señalado en este sentido que la eventual lesión del interés particular del accionista no justifica la pretensión impugnatoria del acuerdo de que se trata, pues no es dable identificar ese interés particular, susceptible de tutela a través de otros medios impugnatorios -y con distinto objeto- diferentes del aquí empleado, con el interés social, que, en palabras del mismo tribunal, "es trascendente al interés individual de los accionistas”. STS (2007) de 29 de marzo de 2007, fundamento Jurídico $2^{\circ}$. En el mismo sentido: STS (1998) de 18 de septiembre de 1998; STS (2000) de 4 de marzo de 2000 y STS (2000) de 29 de noviembre de 2002.

44 Como aclara Jiménez, "el interés social no es la resultante del interés individual de cada socio, utilizado por el contrato de sociedad, sino que es el que está encuadrado en la propia persona jurídica resultante del contrato de sociedad". Por consiguiente -agrega el mismo autor- "cuando hablamos de interés social debemos referirnos a este, que tendrá sus manifestaciones no solamente en la maximalización del beneficio social (...), sino, también, en otros exponentes que no necesariamente se traducen en beneficio, entendido este en su sentido económico". Jiménez De Parga (1995) p. 327.

45 SÁnchez Ruiz (2000) 69 y 70.
} 
No parece aplicable en Chile, por lo mismo, el criterio normativo de aquellas legislaciones como la alemana, mencionada supra, que consideran legítimo el perjuicio que causa una directriz dada a una sociedad filial para beneficiar a la matriz o a otra(s) sociedad(es) del mismo grupo (art. 308.1. AktG $)^{46}$. A la luz de la concepción contractualista que sostenemos para el derecho chileno de sociedades, en efecto, cualquier instrucción que desconozca o vulnere sustancialmente los intereses comunes legítimos ${ }^{47}$ de los socios o accionistas de una sociedad del grupo será contrario al interés social de la misma y, desde allí, incompatible con el interés común del grupo ${ }^{48}$.

\subsection{Responsabilidad DE LAS SOCIEDADES DEL GRUPO Y SUS ADMINISTRADORES DE DERECHO EN EL DERECHO CHILENO. ESTADO DE LA CUESTIÓN}

Muy poco se ha dicho en Chile sobre el régimen de responsabilidad aplicable a las sociedades que interactúan en un grupo empresarial, ya sea en sus relaciones internas, intersocietarias o con terceros. Por de pronto, no existen normas legales diseñadas especialmente para proteger el interés minoritario ni el de los acreedores en el marco de los grupos societarios, que sean distintas del régimen común aplicable a los conflictos de intereses y a las operaciones con partes relacionadas, referido supra ${ }^{49}$. Para salvar esta realidad, la doctrina y la jurisprudencia han planteado diversos caminos, forzando sus presupuestos para encasillar dentro de ellos la problemática que genera la dinámica grupal.

\subsubsection{Responsabilidad extracontractual de las sociedades del grupo y sus administradores}

En primer término, alguna doctrina ha planteado la posibilidad de recurrir a las normas comunes sobre responsabilidad extracontractual del Derecho civil, en el entendido que mediante ellas puede hacerse efectiva la responsabilidad por hecho ajeno (art. 2320 C.C.) de las sociedades de un grupo y la de sus administradores de derecho que, sin ser partes de la relación jurídica entre alguno de los miembros de ese grupo y su acreedor, han interveni-

\footnotetext{
46 En similar sentido el art. 503 N² del Código das Sociedades Comerciais portugués. DE ARriba, fundándose en estas mismas disposiciones legales, coincide en que el perjuicio será legítimo en los casos mencionados en el texto. (De Arriba (2004) p. 219.

47 Por interés legítimo entendemos aquel que resulta conforme con el deber general de fidelidad del socio o accionista para con la sociedad, plasmado en un ejercicio leal de los derechos políticos, económicos y de información. Al respecto Ulmer (1997) p. 186 y ss.

48 En el mismo sentido se plantean por ejemplo los arts. 116 y 117 de la Ley de Sociedades por Acciones de Brasil, $\mathrm{N}^{\circ} 6.404$ de 15 de diciembre de 1976, y más claramente aun los arts. 50 y 51 de la Ley de Sociedades Comerciales uruguaya, $\mathrm{N}^{\circ} 16.060$ de 1989.

49 Puga, reconociendo este mismo déficit, destaca como única situación especial regulada por la ley aquella contemplada en el art. 71 bis de la LSA, referida al derecho de retiro del accionista minoritario cuando un controlador adquiera más del 95\% de las acciones de una SA abierta. En lo demás, plantea la necesidad de recurrir a los mecanismos de protección contemplados en el derecho común. PUGA (2011) p. 669 y ss.
} 
do en aquella como terceros causando un perjuicio ${ }^{50}$. Así lo ha resuelto también en alguna oportunidad la Corte Suprema ${ }^{51}$.

Nos parece, sin embargo, que el criterio apuntado fuerza la esencia misma del grupo empresarial, construido sobre la base de elementos como la dirección unitaria, la influencia dominante y el interés común del grupo que apelan, precisamente, a la existencia de una voluntad única. Tal voluntad, por lo mismo, no admite desmembramientos como el planteado por esta doctrina, los que se presentan en último término como un acomodo forzado a los presupuestos dogmáticos de una responsabilidad aquiliana que, como tal, reclama en este contexto el desdoblamiento hipotético de una voluntad que es esencialmente unitaria. En otros términos, la voluntad del grupo y el interés común que la define no es ni puede ser sustancialmente distinta en lo que a las sociedades agrupadas concierne, las que no deben considerarse por lo mismo como terceros de cara a la actuación de una voluntad que sigue siendo única.

La responsabilidad de la sociedad matriz, que ha impartido en estos casos una instrucción a la filial que resulta lesiva finalmente para esta y/o para un tercero acreedor, no se funda entonces en la condición de tercero absoluto de la primera, sino, mucho más que eso, en su carácter de administradora de hecho de la contratante como se dirá infra, incluyéndose eventualmente la responsabilidad de los administradores de derecho de esta última $^{52}$. En lo que toca a la controlada, que lleva a cabo la instrucción lesiva, esta ejecuta también una conducta que, aunque impuesta como se dijo, la hace responsable de los daños causados a los propios accionistas o a terceros desde que, por esa vía, actúa también el interés de la controladora aunque de manera mediata e indirecta ${ }^{53}$.

50 En este sentido Puga (2011) p. 671; Lyon (2006) p. 76.

51 Por todas, Sentencia Corte Suprema (2010) de 9 de marzo de 2010, Rol No 2423-2008, Considerandos Undécimo y Duodécimo.

52 En Italia, algunos autores han planteado incluso la naturaleza contractual de esta responsabilidad, por incumplimiento de la obligación de correcta gestión societaria y empresarial que el art. 1218 del C.C. le impone a la sociedad holding. Asimilando dicha obligación al deber de protección que recae sobre el médico respecto de su paciente (aun cuando este no haya contratado con aquel sino con el establecimiento de salud del cual depende), sostienen que aunque el hecho generador de la obligación no sea el contrato, en estos casos no podría existir únicamente responsabilidad aquiliana, pues esta no nace -dicen- de la violación de obligaciones sino de la lesión de situaciones jurídicas subjetivas ajenas. Citando la jurisprudencia de la Corte de casación, en fin, se sostiene que cuando se vulneran deberes, la responsabilidad es necesariamente contractual, "porque el sujeto no ha hecho (...) aquello a lo que estaba obligado en virtud de vinculum iuris precedente, según el esquema característico de la responsabilidad contractual (un resumen de esta tesis y de sus promotores puede encontrarse en Galgano (2012) p. 124, nota 59. Sin embargo, hemos dicho ya que la responsabilidad del administrador de hecho puede hacerse efectiva por los accionistas y por los acreedores de las sociedades controladas, lo que supondría extender por ende el estatuto de responsabilidad contractual -de seguirse la tesis planteada- a sujetos indeterminados, lo que no parece acertado.

53 Así lo ha señalado la Corte de casación italiana (por todas, Sentencia de 14 de julio de 1976, N³150, en "Riv. dir. Comm". (1978) p. 220). Muy interesante resulta la sentencia de la misma Corte, que señala que la existencia de una unidad económica, en su noción económica precisamente, tiene su correlato jurídico en la existencia de una única empresa articulada, compuesta no obstante por tantos sujetos empresarios como miembros del grupo existan, encontrándose entre ellos la cabeza del mismo. "La cabeza del grupo -dice la Corte- es, entonces, empresaria por el hecho de ejercer actividad empresarial en su totalidad, en una fase en vía directa [cuando lo hace por sí misma en ejecución de su objeto], en otra fase en modo mediato e indirecto [cuando lo hace a través de sus controladas]" (Sentencia de 26 de febrero de 1990, en “Giur. Comm”. (1991) p. 360). 


\subsubsection{Levantamiento del velo}

La jurisprudencia por su parte, cuando ha debido conocer sobre acciones indemnizatorias en situaciones en que han intervenido sociedades agrupadas, ha recurrido también a la teoría del levantamiento del velo ${ }^{54}$, concebida sin embargo para supuestos y circunstancias que no se avienen siempre y necesariamente con la operativa grupal.

Derivada de la doctrina del disregard of legal entity del derecho norteamericano, el mecanismo jurisprudencial de la desestimación de la personalidad jurídica, conocido también como "levantamiento del velo" o "corrimiento del velo corporativo", no es más que la aplicación de los principios generales sobre abuso del derecho y fraude a la ley, que la jurisprudencia alemana ha venido aplicando también en estos casos -aunque con cierta vacilación- desde mediados del siglo pasado ${ }^{55}$. En palabras de $\mathrm{SERIK}^{56}$, en fin, se abusa de la persona jurídica "cuando los individuos a quienes la norma se dirige se ocultan tras aquella, tanto si ya existía como si solo fue creada para tal fin, con lo que logran sustraerse del mandato legal”.

La figura del grupo empresarial, sin embargo, presupone la concurrencia de diversas sociedades o entes dotados de personalidad jurídica, cuya integración no origina sin embargo un sujeto de derecho autónomo y diferenciado que pueda considerarse como legitimado pasivo de imputación. Por lo mismo, en el caso del grupo como tal no hay velo que descorrer -pues ello presupone una personalidad jurídica que no tiene-, lo que obliga a acotar el ejercicio de levantamiento hipotético del velo al ámbito particular de la personalidad jurídica de la sociedad contratante y de las personas que se ocultan tras ella, socios o accionistas, entre los cuales la cabeza controladora puede figurar o no dependiendo de la estructura del grupo.

En este contexto, por ende, la doctrina del disregard, no obstante su carácter excepcional ${ }^{57}$, recibiría una aplicación de alcances casi ilimitados; o suficientes al menos para trasponer la personalidad jurídica de las diversas fases o eslabones que conforman las sociedades del grupo, hasta llegar a la controladora como sociedad objetivo. Tal expansión, sin embargo, nos parece riesgosa e incluso inconciliable con la noción de persona jurídica en el ordenamiento jurídico chileno ${ }^{58}$, sustentado sobre la base del principio fundamental de la radical separa-

\footnotetext{
54 Por todas, Sentencia Corte Suprema (2009) de 2 de junio de 2009: "3. Esta formulación doctrinaria (levantamiento del velo), que ha tenido también desarrollo en el derecho europeo continental, especialmente en Alemania y España, permite dar solución a situaciones de manifiesto abuso de la personalidad jurídica, en que sociedades aparentemente autónomas e independientes jurídica y económicamente, responden a una misma unidad económica y de organización, porque existe tal control de la una sobre la o las otras, que esta o estas últimas no son sino el 'alter ego' de la dominante, utilizada para obtener un resultado antijurídico. Se previene de este modo abusos del derecho y fraudes a la ley, privilegiándose los principios de supremacía de la realidad y de buena fe (...)".

55 Sobre el particular puede consultarse a SERIK (1958) p. 31 y ss.

56 SERIK (1958) p. 44.

57 Incluso para los tribunales norteamericanos, la desestimación de la personalidad jurídica de la corporation constituye un arbitrio de excepción, aplicable solo en casos extremos y comprobados de fraude a la ley o de uso abusivo de dicha personalidad, más allá de los fines que el ordenamiento jurídico le asigna a la misma (una recopilación de jurisprudencia en este sentido puede encontrarse en SERIK (1958) p. 85 y 86. En Gran Bretaña, más aun, alguna doctrina considera que no existe siquiera un criterio uniforme en las Cortes inglesas, las que aplicarían la teoría del disregard -o reafirmarían por el contrario la separación radical- dependiendo de la empatía que tengan con el caso particular. Véase Dine (2001) p. 28 y ss.

58 Elocuente es en este sentido la sentencia de la Audiencia Provincial de Barcelona, de 11 de marzo de 1998, al señalar: "Los graves problemas que genera la utilización indiscriminada de la técnica de levantar el velo de las
} 
ción entre la sociedad y sus socios o accionistas (art. 2503 inc. $2^{\circ}$ del Código Civil). Se trata, además, de una construcción fundada básicamente en la noción anglosajona de la equidad, sin mayor precisión en cuanto a sus límites y alcances, carente de sistematización ${ }^{59}$ y con supuestos estructurales difíciles de acreditar en el caso concreto, lo que puede llevar a soluciones arbitrarias e inconvenientes de cara al principio recién mencionado.

Por otra parte, el escaso margen que tienen normalmente los acreedores para acceder a la información intra e intersocietaria del grupo, para demostrar precisamente el contexto de apariencia, confusión patrimonial y mala fe que justifica la aplicación de este mecanismo excepcional, les impide muchas veces recurrir a él con alguna expectativa real de éxito. Tal circunstancia, en fin, sumada al sistema de responsabilidad subjetiva o por culpa, los sitúa ante una carga prácticamente imposible de levantar.

Una visión distinta puede plantearse en materia laboral, en cuyo ámbito la jurisprudencia ha sido reiterativa al momento de prescindir de la estructura societaria para privilegiar la realidad fáctica de la relación laboral y con ella al trabajador ${ }^{60}$. En tales casos, sin embargo, no estamos ante la aplicación de la teoría del disregard como podría suponerse, sino ante una figura emparentada con ella aunque distinta, que algunos autores han denominado como enterprise approach ${ }^{61}$. Para esta tesis, concebida como una forma de superar la incertidumbre jurídica generada por el conjunto más o menos irreconciliable de decisiones jurisprudenciales fundadas en la entity law ${ }^{62}$, las empresas del grupo son consideradas como un todo económico unitario, en donde el control que ejerce la sociedad matriz sobre las filiales es lo que determina precisamente la conformación de un grupo y lo que origina, consecuencialmente, la responsabilidad de la dominante por las deudas de las controladas.

\subsection{CONCEPTO DE ADMINISTRADOR DE HECHO Y SUS VARIANTES}

En la práctica societaria no son pocos los casos en que una persona, ajena del todo a los órganos sociales de administración formalmente designados, interviene no obstante en dicha gestión en forma habitual y determinante, al punto que es su voluntad la que prevalece y no la de los administradores que se desempeñan regularmente en dicho cargo. Los primeros son los denominados administradores de hecho, mientras que los otros -los designados según la ley y el estatuto social- los administradores de derecho.

La figura del administrador de hecho no es del todo extraña en la legislación chilena, que la reconoce implícitamente al menos. Así por ejemplo, el art. 99 del Código Tributario considera responsables de delito tributario y hace extensivas las penas penales respectivas no

personas jurídicas, en general, y en los supuestos de grupos de empresas en particular, no permiten generalizar su uso (...), la imputación de deudas de unas sociedades a otras no solo afecta a la posición que ostentan estas frente al demandante, sino también a los acreedores de estas. Por ello, como regla debe mantenerse la eficacia de la personalidad y no cabe imputar las deudas de una sociedad a las demás del grupo".

59 En igual sentido Miguens (2006) pp. 21 y 22, quien rechaza la aplicación de esta teoría a los grupos de sociedades por considerarla "provisional, precaria, asistemática, inorgánica (...) aplicable a los grupos de sociedades solo por una analogía extrema”.

${ }^{60}$ Véase supra, nota 30.

${ }_{61}$ Sobre el sistema de la enterprise law: Blumberg (1992) p. 61 y ss.; Austin (1993) p. 133 y ss.

62 Sobre las diferencias fundamentales entre los conceptos de "entity law" y "enterprice law" puede consultarse a LUTTER (1990) pp. 949-968. 
solo a los gerentes o administradores de derecho del contribuyente persona jurídica, sino también "a quienes hagan las veces de estos", lo que constituye una clara alusión a la figura del administrador de hecho o del administrador oculto o en las sombras. Con todo, la figura señalada carece en nuestro medio de un desarrollo doctrinal y jurisprudencial que permita identificarla como tal y describirla en sus aspectos esenciales, lo que justifica por ende una revisión de su aplicación y desarrollo en el derecho comparado.

Por contrapartida, el fenómeno de una administración formalmente designada, que no coincide sin embargo con la persona que efectivamente administra una sociedad, no es en absoluto novedoso en el derecho comparado. En países europeos como España ${ }^{63}$, Sui$\mathrm{za}^{64}$, Gran Bretaña ${ }^{65}$ y Francia ${ }^{66}$, por poner algunos ejemplos, la figura mencionada tiene expreso reconocimiento normativo. En el ámbito Latinoamericano y del Caribe, países como Argentina ${ }^{67}$, Uruguay $^{68}$, Brasil ${ }^{69}$ y República Dominicana ${ }^{70}$, por nombrar solo algu-

${ }^{63}$ El artículo 236 de la Ley española de Sociedades de Capital, tomado del art. 131 de la derogada LSA de 1989, señala en este sentido: "Art. 236. Presupuestos de la responsabilidad.

1. Los administradores de derecho o de hecho como tales, responderán frente a la sociedad, frente a los socios y frente a los acreedores sociales, del daño que causen por actos u omisiones contrarios a la ley o a los estatutos o por los realizados incumpliendo los deberes inherentes al desempeño del cargo. 2. En ningún caso exonerará de responsabilidad la circunstancia de que el acto o acuerdo lesivo haya sido adoptado, autorizado o ratificado por la junta general".

En materia concursal, se refieren al administrador de hecho los arts. 48.3, $93.2\left(2^{\circ}\right), 164.1,166,172.2\left(1^{\circ}\right)$ y 172.3, todos de la Ley Concursal $\mathrm{N}^{\circ} 22 / 2003$, de 9 de julio.

Especial mención merece también el art. 291 del Código Penal español, que contempla el delito denominado "abuso de mayoría" y, particularmente, el art. 31 del mismo Código, que extiende sustancialmente el ámbito subjetivo de aplicación de la norma penal. Esta norma ha dado lugar a un intenso debate sobre la posible comisión de los señalados delitos por parte de personas jurídicas, cuando actúan precisamente como administradoras de hecho de otras. Sobre el particular puede consultarse a GarCía Cavero (1999) p. 70; Ríos CorBАСНО (2005) p. 39 y ss. En Italia, por su parte, la jurisprudencia ha equiparado la responsabilidad penal del administrador de hecho con la que le corresponde al de derecho, declarando que en una sociedad la gestión real y efectiva de administración prevalece sobre los aspectos puramente formales de asunción del cargo (por todas Sentencia del Tribunal Supremo italiano, Sala de lo Penal, de 29 de diciembre de 1972, en Giustizia penale (1973) p. 591).

${ }^{64}$ Véase art. 754 del Código Suizo de Obligaciones.

65 Véase Sec. 741 de la Companies Act, de 1985.

${ }^{66}$ Los arts. 180 y 182 de la Ley de 25 de enero de 1985 (Redressement Judiciarie) considera como administrador de hecho a todo aquel que dirige una sociedad sin haber sido regularmente investido como tal. En el ámbito jurisprudencial, emblemático es también el denominado caso Rosenblum, que dio origen a la doctrina del mismo nombre, en donde la Cour de Cassation, Sala Criminal, condenó al controlador por la insolvencia provocada a sociedades contraladas del grupo. Véase Revue des Sociétés (1985) p. 648 y ss.

${ }^{67}$ Sin referirse explícitamente al administrador de hecho, la Ley de Sociedades Comerciales argentina, $\mathrm{N}^{\circ}$ 19.550 de 1984 (B.O. de 30 de marzo), contempla dicha figura en su art. 54: "Art. 54 . El daño ocurrido a la sociedad por dolo o culpa de socios o de quienes no siéndolo la controlen constituye a sus autores en la obligación solidaria de indemnizar sin que puedan alegar compensación con el lucro que su actuación haya proporcionado en otros negocios. (...)".

${ }^{68}$ La ley uruguaya sobre Sociedades Comerciales, referida supra ( $\mathrm{N}^{\circ} 16.060$, de 1989), sin referirse explícitamente al administrador de hecho, contempla dicha figura en los arts. 50 y 51, a propósito de las sociedades controladoras y controladas precisamente. La Ley de Quiebras, $\mathrm{N}^{\circ} 18.387$ de 23 de octubre de 2008, menciona expresamente al administrador de hecho en sus arts. 112.2.b, 192, $201 \mathrm{y}$ art. 208.

69 Véase Ley de Sociedades Anónimas, de 1976, art. 276.

70 Prácticamente todos los artículos del Capítulo III de la Ley General de las Sociedades Comerciales y Empresas Individuales de Responsabilidad Limitada, № 479-08, sobre "Infracciones comunes a los diversos tipos 
nos, han incorporado también en sus legislaciones la figura del administrador de hecho, de manera explícita o implícita.

La doctrina define a los administradores de hecho como "aquellas personas que, sin ocupar o controlar formalmente el órgano de la sociedad, ejercen, por cualquier vía, una influencia decisiva que determina la decisión o las decisiones que ocasionan el daño a la sociedad"71. Según el TS español, por su parte, son administradores de hecho "(...) los que, habiendo ostentado formalmente el cargo, se vieran privados de su titularidad por nulidad de la designación o finalización del mandato, si, de hecho, siguen ejerciendo las mismas atribuciones. También pueden ser tenidos por administradores de hecho los que actuan como tales, sin previo nombramiento o designación, si su actuación como tales administradores, además, se desenvuelve en condiciones de autonomía o independencia y de manera duradera en el tiempo"72.

Tomando como base esta descripción entonces, la administración de hecho de una sociedad admite dos versiones distintas:

\subsubsection{Concepto restringido: administrador aparente o notorio.}

En su concepción tradicional, formalista y restringida ${ }^{73}$, se considera administrador de hecho a aquel que ejerce la función propia de los administradores pese a haber perdido tal condición, en razón de la nulidad o caducidad de su designación. Hablamos en estos casos del administrador aparente o notorio, que de algún modo recoge el art. 34 de la LSA chilena al prorrogar la vigencia de las funciones de aquellos directores cuyo periodo legal o estatutario hubiere vencido. Según esta idea originaria del administrador de hecho, entonces, lo importante es evitar que la falta o imposibilidad de los administradores sociales provoque la inmovilización de la sociedad, permitiéndose mediante esta figura la continuidad de la empresa ${ }^{74}$.

\subsubsection{Concepto amplio: administrador oculto o en las sombras.}

Una visión más reciente, amplia y funcional, fruto principalmente de la labor doctrinal y jurisprudencial en Italia $^{75}$ y recogida por prácticamente todas las legislaciones europeas, atiende únicamente a las funciones administrativas de facto que realiza efectivamente el sujeto, sin importar si este ha sido nombrado o no como tal administrador. Según esto, será administrador de hecho quien ejerce funciones de administración de una sociedad, realizando actos de gestión sin haber sido formalmente investido como tal administrador en conformidad a la ley y al estatuto social. Se trata en este caso de la figura del administrador oculto, que proponemos precisamente para los grupos empresariales en

\footnotetext{
de sociedades comerciales", mencionan expresamente a los administradores de hecho como sujetos pasivos de responsabilidad.

71 Pérez Idiartegaray (2004) p. 116.

72 Sentencia TS español (2010) de 25 de junio de 2010 (FJ 7.2), Recurso de Casación núm. 519/2009.

73 Cfr. Fuentes (2006) pp. 291 y 292. Para López, es administrador aparente o notorio -según esta concepción restringida- aquel que "careciendo de un nombramiento regular, ejerce de forma directa, continuada e independiente, sin oposición de la sociedad, una actividad positiva de gestión, idéntica o equivalente a la que ejerce un administrador de la sociedad formalmente constituido”. López Rodríguez (2012) p. 217.

74 Véase Latorre (2003) p. 5.

75 Por todos Bonelli (1985) p. 259.
} 
Chile en cuanto marco dogmático que permite definir el régimen de responsabilidad de las sociedades controladoras y sus administradores de derecho.

En efecto, uno de los mecanismos más recurrentes en la práctica, para eludir la responsabilidad propia de los administradores de derecho, lo constituye precisamente la administración de hecho o fáctica. Ante esta realidad, los presupuestos subjetivos y materiales de la doctrina del administrador de hecho han sido ampliados como una forma de ajustar el régimen de responsabilidad por daño a las características y particularidades que presenta este fenómeno, haciéndola extensiva por lo mismo a aquellos casos en que es la realidad fáctica la que modela y describe en último término el verdadero engranaje de toma de decisiones sociales. Lo relevante en este caso es la existencia de una actividad real y autónoma de administración ${ }^{76}$, realizada por quien no tiene el carácter de administrador formalmente constituido y que, no obstante, resulta responsable aun cuando su gestión se encuentre extramuros del régimen de responsabilidad aplicable a los administradores formalmente designados. Constituye, por ende, la receta adecuada para un diagnóstico acotado, o, como señala Latorre ${ }^{77}$, "un remedio a la elusión de responsabilidades cuya finalidad es imputar responsabilidad al sujeto que ejerce las funciones propias de un administrador sin serlo".

Dentro de esta figura del administrador oculto, con todo, pueden subdistinguirse otras dos que le son propias, pero que se diferencian entre sí dependiendo del ropaje que utilice $-\mathrm{o}$ no- el agente:

A) Una primera sub-figura es la del administrador de hecho que actúa como tal, aunque oculto tras una forma o figura distinta dentro de la sociedad (v. gr. factor, gerente, apoderado, ejecutivo, etc.).

Alguna doctrina advierte en esta parte, con todo, que la sola existencia de un vínculo laboral de subordinación y dependencia, entre la sociedad y quien ejerce esta función administrativa oculta, descarta por completo la figura del administrador de hecho. Este último -dicen-, requiere de autonomía de gestión para ser considerado como tal (vid. infra), la que no se daría en los casos apuntados ${ }^{78}$.

La afirmación nos parece en principio acertada aunque no absoluta, si se considera que en estos casos el ropaje formal del agente será normalmente el medio que este utiliza para desempeñar la gestión oculta de administración. La autonomía, por ende, no desaparece necesariamente por la relación laboral, de manera que siempre será posible demostrar que dicha subordinación es una apariencia más, utilizada precisamente para ocultar una realidad que es distinta ${ }^{79}$.

B) La otra posibilidad, común en el caso de los grupos empresariales, es aquella en donde el administrador de hecho no recurre a ningún ropaje formal externo, sino que actúa en las sombras y sin dejar rastros palpables de su gestión. Se trata aquí del

\footnotetext{
76 Véase Gallego (2002) p. 154 y ss.; García-Cruces González (2005) p. 4.936; Perdices Huetos (2002) p. 134 y ss; García CaVero (1999) p. 119 y ss.

77 Latorre (2003) p. 16.

78 Por todos, EsPinós Borrás (2005) pp. 96-99.

79 En el mismo sentido López (2012) p. 219.
} 
administrador absolutamente oculto, frente al cual los administradores de derecho se presentan como meros ejecutores de una voluntad impuesta y decisiva.

\subsubsection{Elementos comunes del administrador de hecho: autonomía y permanencia}

Por último, y siguiendo con la descripción de la sentencia del TS español, citada supra, la figura del administrador presenta dos elementos concurrentes, que la identifican precisamente: la autonomía o independencia y la permanencia.

A) El actuar del administrador de hecho debe ser autónomo.

Esto quiere decir que el administrador de hecho debe realizar su gestión sin influencia de terceros y sin seguir, por ende, las directrices o instrucciones de los administradores de derecho. En palabras de Pertiñez ${ }^{80}$, el administrador de hecho realiza "funciones propias de la administración social, con una cierta extensión y continuidad y de manera autónoma, es decir, sin subordinación a un órgano de administración social”.

B) Estabilidad o permanencia en el tiempo.

Como señala la sentencia del TS español, citada supra, la figura del administrador de hecho supone una actuación duradera en el tiempo, descartándose por ende las instrucciones eventuales, aisladas y ocasionales. Así lo sostiene también alguna doctrina ${ }^{81}$. No compartimos sin embargo este criterio, pues además de fundarse en un elemento difuso como es el límite temporal entre lo permanente y lo pasajero, agrega una exigencia que en nada altera - de no concurrir- la conducta del administrador de hecho en sí. Por lo mismo, si el daño provocado a la sociedad del grupo y/o a sus accionistas y acreedores se origina causalmente en una instrucción dolosa o culpable dada por el controlador a la filial, aquella, aunque sea ocasional -o incluso única-, podrá ser también fuente de responsabilidad para este último y/o para sus administradores de derecho.

\subsection{Supuestos subjetivos de la administración de hecho: Responsabilidad}

DE LA SOCIEDAD CONTROLADORA Y RESPONSABILIDAD AUTÓNOMA DE SUS ADMINISTRADORES DE DERECHO

De lo dicho hasta aquí puede concluirse que la figura del administrador de hecho apunta a la construcción de un estatuto particular y sustancial de responsabilidad, tutelar de los intereses sociales, de los accionistas y de los acreedores. No se trata ya de ajustar los presupuestos del disregard al ámbito de la relación intersocietaria o grupal, ni de forzar la naturaleza misma de las estructuras de grupo para sancionar al controlador y/o a sus administradores de derecho por la vía extracontractual del hecho ajeno, sino de imputar responsabilidad directa tanto a la sociedad dominada que ejecuta el acto dañoso y contrario a la buena fe en el tráfico mercantil, como también a aquella que lo determina en un contexto de dirección unitaria y a sus administradores de derecho.

\footnotetext{
80 Pertiñez (2009) pp. 15-49.

81 Véase, Díaz Echegaray (2002) p. 41 y 42.
} 


\subsubsection{La sociedad controladora como administrador de hecho de las sociedades dominadas. La cuestión del onus probandi}

De lo dicho hasta aquí podemos concluir ya con Galgano ${ }^{82}$ que "la incorrecta gestión empresarial y societaria (...) no es solo la mala gestio de los administradores, elevada a fuente de responsabilidad por el derecho societario, sino también, el mal gobierno del grupo por la asamblea del holding, cuyas decisiones en materias de su competencia -operaciones sobre el capital, fusiones, escisiones, etc.- pueden provocar desequilibrios entre las sociedades del grupo".

Especial incidencia tiene entonces esta concepción del administrador de hecho de cara a la labor probatoria que le corresponde a quien pretenda invocar en juicio la responsabilidad del controlador y/o de sus administradores de derecho, siempre difícil y en muchos casos imposible dada la falta de información (vid. supra). Tal vez si en un futuro próximo, el criterio procesal de la carga dinámica de la prueba o de disponibilidad y facilidad probatoria, que se contiene actualmente en el Proyecto de Código Procesal Civil chileno $^{83}$, contribuya a aliviar esta situación. Sin perjuicio de ello, a través de la figura del administrador de hecho la sola constatación de la existencia del grupo permite presumir en ciertas ocasiones, iuris tantum, la responsabilidad del controlador y sus administradores, de quienes es dable esperar precisamente un estándar objetivo de diligencia al momento de diseñar e impartir sus directrices a las filiales del grupo ${ }^{84}$.

No se trata, por cierto, de hacer extensiva la responsabilidad del controlador en todo caso, pues la regla debe ser precisamente la inversa. Sin embargo, en aquellos casos en que se obliga a la filial a actuar en perjuicio de su propio interés y en contra de un interés grupal fundado en políticas comunes y coherentes, nos parece que se habrá traspasado el umbral objetivo de diligencia recién señalado, marcado por la buena fe en el cumplimiento de los deberes fiduciarios exigibles en general a los administradores de una sociedad individualmente considerada ${ }^{85}$. No pretendemos tampoco aplicarle íntegramente al administra-

82 Galgano (2012) pp. 122 y 123

83 Dice el inciso $2^{\circ}$ del art. 294 del Proyecto, en actual trámite legislativo: "Carga de la prueba. (...)

El tribunal podrá distribuir la carga de la prueba conforme a la disponibilidad y facilidad probatoria que posea cada una de las partes en el litigio lo que comunicará a ellas, con la debida antelación, para que asuman las consecuencias que les pueda generar la ausencia o insuficiencia de material probatorio que hayan debido aportar o no rendir la prueba correspondiente de que dispongan en su poder". (Boletín N8197-07, Primer Trámite Constitucional).

84 En el sistema inglés, esta dificultad probatoria ha llevado a incorporar en la ley concursal -Insolvency Act de 1986- la figura del wrongful trading, contemplada en la Sec. 214. Por esta vía, el legislador estableció un estándar objetivo de diligencia de los administradores dirigentes (esto es, los que dirigen los negocios de la sociedad, por oposición a los que no lo hacen), exigible tanto al administrador de derecho (Sec. 251) como también al de hecho o "shadow director" (Sec. 215), sin necesidad de acreditar necesariamente un propósito fraudulento. La figura no alcanza en todo caso a imponer responsabilidad al shadow o de facto director, pero faculta al juez para exigirle una contribución suficiente como para equilibrar los activos realizables y los pasivos exigibles de la sociedad controlada en insolvencia. Véase Prentice (1991) pp. 77-79.

$85 \mathrm{El}$ art. 311.1 de la AktG señala en este sentido, como límite precisamente a la influencia dominante:

"1. En ausencia de un contrato de dominación, la empresa dominante no puede utilizar su influencia para inducir a una sociedad dependiente, anónima o comanditaria por acciones, a que concluya un negocio jurídico o adopte medidas en perjuicio suyo u omita uno y otras, a no ser que se compensen los perjuicios". Trad. EMBID IRUJo (2010).

El art. 51 de la Ley de Sociedades uruguaya, ya citada, señala a su vez: 
dor de hecho el estatuto jurídico del administrador de derecho, pues ello se prestaría para contrasentidos, sino solo aquella parte que regula y disciplina la función de gestión de la actividad social, o, como señala Fuentes ${ }^{86}$, "aquellos deberes en los que prevalece el aspecto sustancial del fenómeno". Fuera quedan por ende los aspectos formales de la función de administración, como las citaciones a junta, publicaciones en tiempo y forma, etc., que obviamente no puede realizar quien no detenta formalmente el carácter de administrador.

En otros términos, y como lo ha sostenido precisamente el Foro Europeo, es obligación del controlador el mantener un equilibrio entre los intereses de las distintas sociedades del grupo, distribuyendo las oportunidades y las cargas de manera tal que ninguna de ellas termine asumiendo riesgos desproporcionados ${ }^{87}$. De lo contrario, la conducta del administrador de hecho deviene en una ilicitud imputable, sin necesidad que se acredite adicionalmente la concurrencia de un ánimo especial a su respecto, lo que implica que en tales casos deba invertirse además la carga de la prueba. Dicho de otra forma, si las directrices dadas por la controladora han llevado a la controlada a realizar conductas o a celebrar negocios jurídicos perjudiciales para esta última, debe presumirse iuris tantum la responsabilidad de la primera y de los administradores que hayan inducido a la dominada a realizar los actos descritos, a menos que tales perjuicios sean debidamente compensados por la dominante dentro del mismo ejercicio en que se causaron ${ }^{88}$.

"Art. 51. (Obligaciones de la sociedad controlante. Responsabilidades). La sociedad controlante deberá usar su influencia para que la controlada cumpla su objeto, debiendo respetar los derechos e intereses de los socios o accionistas. Responderá por los daños causados en caso de violación de estos deberes y por los actos realizados con abuso de derecho. El o los administradores de la sociedad controlante serán solidariamente responsables con ella cuando infrinjan esta norma. (...)".

Por último, el art. 2497 del CC. italiano señala en el mismo sentido:

"1. Las sociedades o los entes que, ejerciendo actividad de dirección y coordinación de sociedad actúan en el interés empresarial propio o ajeno en violación de los principios de correcta gestión social y empresarial de las sociedades mismas, son directamente responsables frente a los socios de estas por el perjuicio causado a la rentabilidad y al valor de la participación social, como también respecto de los acreedores sociales por la lesión causada a la integridad del patrimonio de la sociedad. No hay responsabilidad cuando el daño resulta faltar a la luz del resultado total de la actividad de dirección y coordinación o bien ha sido integralmente eliminado a causa de operaciones en esa dirección.

2. Responde solidariamente quien haya tomado en todo caso parte al hecho injurioso y, en los limites de la ventaja conseguida, quien haya llevado conscientemente de ello beneficio.

3. El socio y el acreedor social pueden actuar contra la sociedad o el ente que practica la actividad de dirección y coordinación, solo si no han sido satisfechos por la sociedad sometida a la actividad de dirección y coordinación.

4. En el caso de quiebra, liquidación forzosa administrativa y administración extraordinaria de sociedad sometida a ajena dirección y coordinación, la acción debida a los acreedores de este es ejercida del curador o del comisario a liquidador o del comisario extraordinario".

86 Fuentes (2006) p. 305. En igual sentido Latorre (2003) pp. 188 y 189; Bonelli (1992) p. 112.

87 Véase LutTer (1999) p. 22.

${ }^{88}$ El régimen de responsabilidad y carga de la prueba aquí propuesto se encuentra contemplado expresamente en la Ley de Sociedades Anónimas alemana (Aktiengesetz), artículos 317 y 318, que hace responsables de los perjuicios no compensados causados a la sociedad dominada y a sus accionistas a la sociedad dominante y, solidariamente, a los administradores de derecho que han inducido a ejecutar las directrices perjudiciales. Respecto de estos últimos, el art. 318.1 señala: "Los miembros de la Dirección de la sociedad responderán solidariamente con los obligados a indemnizar según el artículo 317, cuando, con infracción de sus obligaciones, hayan omitido recoger en el informe sobre las relaciones de la sociedad con las empresas vinculadas en negocio jurídico o las medidas perjudiciales, o indicar que la sociedad fue perjudicada por el negocio jurídico o por las medidas, y que el daño no se 


\subsubsection{Los administradores de derecho de la sociedad controladora como} administradores de hecho de las sociedades dominadas

Especial atención requiere la situación en que se encuentran los administradores de derecho de la controladora/administradora de hecho, pues la responsabilidad de aquellos varía sustancialmente según cual sea la posición que asumen en cada caso, incluso dentro de un mismo tipo societario.

Uno de los principales aspectos que postula la teoría organicista de la sociedad, en efecto, radica en la autonomía funcional de la que están dotados los diversos órganos que la conforman, lo que en la sociedad anónima se traduce concretamente en que el directorio, como órgano de administración, es independiente de la junta de accionistas y por ende soberano al momento de adoptar aquellas decisiones que la ley coloca en su concreta esfera competencial. Por tal razón, y considerando además que tales administradores pueden ser personas distintas de las que componen a su vez la mencionada junta de accionistas - como ocurre normalmente en las sociedades abiertas-, bien puede ocurrir que las voluntades manifestadas por cada uno de dichos órganos no sean necesariamente coincidentes entre sí. Todavía más, entre la voluntad de uno y otro órgano y el interés particular de los accionistas y administradores puede plantearse también una situación de conflicto que deberá abordarse, a su vez, teniendo en cuenta un interés social concurrente que no necesariamente habrá de coincidir con el interés particular recién mencionado, o con el manifestado por el órgano de administración o por la mayoría de la junta.

Especial relevancia tiene este fenómeno en las sociedades anónimas abiertas y más aún en las cotizadas, donde es frecuente observar una radical separación entre la propiedad accionaria y el poder de gestión que le corresponde a los administradores. Si bien el modelo normativo de la sociedad anónima le entrega a la junta de accionistas la designación y control de estos últimos, tales facultades, como apunta Sánchez ${ }^{89}$, “devienen inoperantes ante la configuración interna propia de determinadas sociedades anónimas abiertas, caracterizadas por la dispersión y absentismo del conjunto de su numeroso accionariado”.

Se plantea en estos casos, en síntesis, el denominado problema de agencia, "dado que el control y la propiedad de una sociedad no siempre pertenecen al mismo agente" ${ }^{\text {. }}$. El interés de los administradores se distancia en ocasiones del interés de los accionistas, aun cuando ambos -administradores y accionistas- se necesiten recíprocamente. En algunos modelos de sociedad anónima abierta, en efecto, con accionariados fuertemente atomizados, el interés preponderante de los accionistas se focaliza mayormente en la rentabilidad de la inversión y no en el ejercicio efectivo de los derechos políticos y de control ${ }^{91}$, lo que se

compensó. Si resulta controvertida la aplicación de la diligencia de un administrador ordenado y leal, les incumbirá la carga de la prueba”. Traducción de EMBID (2010) p. 188. Sobre el alcance de estas normas legales puede consultarse a KÜBLER (2001) p. 611 y ss.

89 SÁnchez Ruiz (2000) pp. 44 y 45.

90 Pfeffer Urquiaga (2001) p. 8. Los inversionistas -agrega este autor- necesitan el capital humano de los administradores para generar rentas sobre su capital. Por otra parte, los administradores necesitan los recursos entregados por los inversionistas para realizar sus proyectos de negocios".

91 A estos accionistas BRUNETTi los califica como "especuladores" o pequeños ahorrantes, que no quieren participar en la vida social sino especular simplemente con la cotización de las acciones. Para estos -dice este autor-, 
traduce eventualmente en una fuerte autonomía y protagonismo de los administradores y, consecuencialmente, en la desnaturalización de las facultades legales de la junta de accionistas, que se limita en último término a ratificar lo que aquellos actúan. Más aun, en tales casos, de capital disperso, los conflictos de intereses al interior de la sociedad no se producen normalmente entre accionistas que reclaman la tutela de sus respectivos derechos políticos y patrimoniales, sino entre estos y los administradores de derecho y de hecho que los vulneran en beneficio propio.

En otros modelos en cambio, con estructuras internas en donde el capital accionario se reparte entre un grupo reducido de accionistas minoritarios interesados en la gestión (denominados por la doctrina como accionistas empresarios ${ }^{92}$ ) y otros tantos que buscan simplemente rentabilizar su inversión (llamados accionistas inversores), la administración estará controlada normalmente por los primeros aun cuando ninguno de ellos, por sí solo, tenga un porcentaje mayoritario del accionariado. En esos casos, que la doctrina reconoce como sociedades anónimas de capital concentrado, los conflictos societarios no solo podrán generarse entre los administradores y los accionistas inversores o no controladores (como sería el caso en que los accionistas empresarios instrumentalicen la función de los administradores para desviar oportunidades de negocio hacia entidades del grupo, o viceversa, o para vaciar el patrimonio social mediante enajenaciones -también relacionadas- a precios muy por debajo de los de mercado), sino también entre estos últimos y los que detentan el señalado control.

En síntesis, nos parece que los administradores de derecho de la sociedad controladora, que imparte las directrices dañosas a sus filiales o dependientes dentro del mismo grupo, podrán considerarse como administradores de hecho en la medida que su actividad reúna los requisitos de autonomía a que nos hemos referido supra, sin perjuicio del régimen común de responsabilidad que pueda aplicárseles en los demás casos.

\section{CONCLUSIONES}

1. La existencia y legitimidad de los grupos empresariales, como derivación del fenómeno del control y de las personas relacionadas, se encuentra expresamente consagrada en la legislación chilena. Pese a ello, no existe un tratamiento legal, doctrinal ni jurisprudencial que, recogiendo precisamente las características, los elementos y la realidad misma de la dinámica grupal, permita aplicar en dicho contexto un estatuto acotado y diferenciado de responsabilidad, tanto a las sociedades dominantes como a sus administradores de derecho, en aquellos casos en que sus directrices han causado un perjuicio a las sociedades dominadas y sus accionistas.

2. Ante el vacío recién mencionado, la jurisprudencia ha debido recurrir en algunos casos a institutos asistemáticos como el levantamiento del velo de la persona jurídica o, en

el mayor incentivo al momento de adquirir una participación accionaria está dado por la facilidad e inmediatez de la negociación de los títulos que se transan en Bolsa, lo que explica que esta categoría de accionistas se encuentre normalmente en las sociedades abiertas y cotizadas. BRUNETTI (1960) p. 46.

92 Por todos, Ascarelli (1936) p. 10. 
otros, a estatutos normativos como la responsabilidad extracontractual por hecho ajeno, los que sin embargo no se ajustan a las concretas características de la figura grupal ni a su dinámica particular. Con ello, por lo mismo, se fuerzan necesariamente los fines y el diseño mismo de tales herramientas e institutos, concebidos en último término para conflictos de intereses surgidos en el seno de sociedades aisladas (entity law) y no para la realidad de aquellas sociedades integradas a un grupo (enterprise law), lo que se traduce en último término en soluciones inadecuadas y en resultados que tienden a incentivar eventualmente el abuso del poder dominante.

3. Reconociendo la situación anterior, la mayoría de los ordenamientos europeos e incluso del concierto latinoamericano han incorporado en sus legislaciones internas la figura del administrador de hecho, en su concepción amplia, considerando como tales a la sociedad dominante del grupo y a sus administradores de derecho. La tendencia general en este sentido se traduce en la creación de un estatuto diferenciado de responsabilidad respecto de la sociedad dominante y de sus administradores, caracterizado -con ciertos maticespor la obligación de indemnizar que se le impone a la sociedad dominante por los perjuicios no compensados causados a la filial -por una parte-, y por la responsabilidad solidaria que se establece para aquellos administradores que han inducido el actuar de las sociedades dominadas mediante directrices que trasponen el umbral objetivo de un ejercicio lícito del poder de dominación.

4. La figura del administrador de hecho debe ser incorporada al derecho chileno de sociedades y particularmente al derecho de grupos, en cuanto mecanismo ajustado a la realidad y dinámica de estos últimos y superador de las restricciones que imponen los arbitrios mencionados supra, propios de un derecho tradicional orientado a la sociedad aisladamente considerada. La correcta aplicación de esta figura, con todo, supone una necesaria distinción entre el interés de los accionistas, de los administradores, de las sociedades agrupadas y el interés del grupo propiamente tal, lo que permitirá definir a su vez la responsabilidad que puede imputarse a la sociedad dominante y/o a sus administradores de derecho, según el caso.

Esta incorporación, por último, debe ir acompañada necesariamente de un tratamiento normativo también diferenciado en cuanto a quién debe asumir la carga de la prueba al momento de hacer efectiva la responsabilidad del administrador de hecho. Considerando en este sentido las restricciones de información que eventualmente pueda imponer el ente controlador y, por ende, las dificultades que deberá enfrentar en tal sentido el demandante que pretenda acceder a ella, consideramos que dicha carga probatoria deberá recaer en el administrador de hecho cuyos deberes de lealtad, diligencia y cuidado, en cuanto obligaciones aplicables a todo administrador, resulten controvertidos.

La figura del administrador de hecho, por lo demás, no es del todo ajena en Chile, pues se la contempla implícitamente en el art. 99 del Código Tributario. Sin embargo, su importancia dogmática y su utilidad práctica aconsejan incorporarla expresamente como fuente directa de responsabilidad en nuestra legislación sobre sociedades, mercado de valores y libre competencia, en términos amplios, facilitando por esta vía la labor probatoria de 
los sujetos afectados del grupo -y/o sus accionistas o acreedores- y la efectiva sanción patrimonial del administrador oculto.

\section{BIBLIOGRAFÍA}

Alcalde Rodríguez, Enrique (2007): La sociedad anónima. Autonomía privada, interés social y conflictos de interés (Santiago, Editorial Jurídica de Chile).

Austin, R.P. (1993): "Problems for directors within Corporate Groups", en: Michael Gillooly (edit.), Law Relating to Corporate Groups (Sidney, The Federation Press).

Blumberg, Phillip (1992): The American Law of Corporate Groups (Sidney, Continuing Legal Education, University of Sidney, Faculty of Law).

Bonelli, Franco (1985): Gli amministratore di società per azioni (Milán, Giuffrè).

Bonelli, Franco (1992): "La responsabilità degli amministratori di società per azioni”, en: Quaderni di Giurisprudenza commerciale (Milán, Giuffrè).

Brunetti, Antonio (1960): Tratado del Derecho de Sociedades (trad. Felipe de Solá Cañizares, Buenos Aires, Uteha).

De Arriba Fernández, María Luisa (2004): Derecho de Grupos Sociales (Madrid, Thomson-Civitas).

Díaz Echegaray, José Luis (2002): El administrador de hecho de las sociedades (Cizur Menor-Navarra, Aranzadi).

Dine, Janet y Koutsias, Marios (2001): Company Law (Reino Unido, Palgrave Macmillan, cuarta edición).

Domínguez Ruiz De Huidobro, Adolfo (2002): "Cuestiones sobre la responsabilidad de los administradores de los grupos de sociedades. Particular referencia a la teoría del administrador de hecho", en Derecho de Sociedades. Libro Homenaje a Fernando SánchezCalero, Vol. II (Madrid, McGraw-Hill) p. 1299-1321.

Duque Domínguez, Justino (1987): "Los problemas generales planteados por los grupos, con especial referencia al Derecho mercantil”, en: Grupos de sociedades. Su adaptación a las normas de las comunidades europeas (Alcalá de Henares, Confederación Española de Organizaciones Empresariales, Universidad de Alcalá de Henares, Facultad de Derecho) pp. 13-61.

Embid Irujo, José Miguel (1986): "El Régimen jurídico de los grupos de sociedades en la CEE”, en García de Enterria, E., González Campos, J.D. y Muñoz Machado, S. (coord.), Tratado de Derecho Comunitario Europeo, T. II (Madrid, Civitas) pp. 73-110.

Embid Irujo, José Miguel (2010): Ley Alemana de Sociedades Anónimas (Madrid, Marcial Pons).

EsPinós Borrás De QuAdras, Álvaro (2005): La responsabilidad civil en las sociedades mercantiles (Barcelona, Bosch).

EucKen, Walter (1952): Grundsätze der Wirtschaftspolitik (Herausgegeben von Edgar Salin und Arthur Spiethhof) (Berna, A. Franque AG. Editores).

Fuentes Naharro, Mónica (2006): "Una aproximación al concepto de administrador de hecho y a la funcionalidad de la figura en los grupos de sociedades", en Gobierno Corporativo y Crisis Empresariales (II seminario Harvard Complutense de Derecho Mercantil) 
(Madrid, Departamento de Derecho mercantil de la Universidad Complutense, Marcial Pons) pp. 289-308.

Galgano, Francesco (2012): "Introducción. La Empresa de Grupo", en: Los Grupos Societarios. Dirección y coordinación de Sociedades, Libro homenaje a Francesco Galgano (trad. Hugo Aguirre y María de la Colina, Bogotá, Universidad del Rosario, segunda edición) pp. 22-90.

Gallego Soler, J. Ignacio (2012): "El concepto de administrador de hecho como criterio de imputación de la autoría en Derecho penal", en: Corcoy Bidasolo, Mirentxu (dir.), Derecho penal de la empresa (Pamplona, Universidad Pública de Navarra) p. 163 y ss.

García Cavero, Percy (1999): La responsabilidad penal del administrador de hecho de la empresa: criterios de imputación (Barcelona, Bosch).

García-Cruces González, J. Antonio (2005): "Concursado, cómplices y personas afectadas por la calificación (en torno al ámbito subjetivo del concurso culpable)”, en: GARCía Villaverde, R., Alonso Ureba, A., Pulgar Ezquerro, J. (coord.), Estudios sobre la Ley concursal, Libro homenaje a Manuel Olivencia, Vol. 5 (Madrid, Marcial Pons, Ediciones Jurídicas y Sociales) p. 4913-4946.

Garrani, Giuseppe (1939): Tecnica amministrativa societaria. Appunti delle lezioni di tecnica amministrativa societaria tenute negli anni accademici 1934-35 e 1935-36. Corso per dirigenti di aziende (Padua, Cedam).

Gerber, David J. (1994): "Constitutionalizing the Economy: German Neo-liberalism, Competition Law and the 'New' Europe", American Journal of Comparative Law, Vol. 42: p. 33 y ss.

Gerum, Elmar (1988): Mitbestimmung und Corporate Governance (Gütersloh, Bertelsmann Stiftung).

Girgado Perandones, Pablo (2001): La empresa de grupo y el Derecho de sociedades (Granada, Comares).

Girgado Perandones, Pablo (2002): La responsabilidad de la sociedad matriz y de los administradores en una empresa de grupo (Madrid, Marcial Pons).

JAEGER, Pier Giusto (1964): L'interesse sociale (Milán, Giuffrè).

Jequier Lehuedé, Eduardo (2013): El Arbitraje en el derecho Chileno de Sociedades. Arbitrabilidad del conflicto societario mercantil (Santiago de Chile, Thomson Reuters - LegalPublishing).

Jiménez De Parga, Rafael (1995): "La impugnación de los acuerdos sociales en la Ley reguladora de la Sociedad Anónima”, en: Estudios Jurídicos sobre la Sociedad Anónima (Madrid, Civitas).

KüBlER, Friederich (2001): Derecho de Sociedades (trad. Michèle Klein, Madrid, Fundación Cultural del Notariado, quinta edición).

Latorre Chiner, Nuria (2003): Los administradores de hecho en las sociedades de capital (Albolote - Granada, Comares).

López Rodríguez, Carlos (2012): "El accionista único como administrador de hecho en el derecho uruguayo", en: JeQUiER Lehuedé, Eduardo (coord.), “Cuadernos de Extensión Jurídica”, N²2 (Santiago, Facultad de Derecho Universidad de Los Andes) pp. 207-227. 
LutTer, Marcus (1989): Ein Konzernrecht für Europa: Symposion (Bonn, Zentrum für Europäisches Wirtschaftsrecht, Rheinische Friedrich-Wilhelms-Univ.).

LutTer, Marcus (1990): “Enterprise Law Corp. v. Entity Law, Inc. - Phillip Blumberg's Book from the Point of View of an European Lawyer", The American Journal of Comparative Law, Vol. 38, N4: pp. 949-968.

Lyon Puelma, Alberto (2006): Personas Jurídicas (Santiago de Chile, Ediciones Universidad Católica de Chile, cuarta edición).

Machado Plazas, José (2006): El concurso de acreedores culpable: calificación y responsabilidad concursal (Cizur Menor - Navarra, Thomson Civitas).

MAnara, Ulisse (1902): Delle società e delle associazioni commercial: trattato teorico-pratico (Torino, Unione Tipografico-Editrice).

Massaguer Fuentes, José (1989): "La estructura interna de los grupos de sociedades. (Aspectos jurídico-societarios)", Revista de Derecho Mercantil, № 192: pp. 281-325.

Miguens, Héctor José (2006): Extensión de la Quiebra y responsabilidad de los Grupos de Sociedades (Buenos Aires, LexisNexis, segunda edición).

MÖHRING, Ludwig (1992): Schutz der Gläubiger einer konzernabhängigen GmbH (Berlín, Duncker \& Humblot).

Montalenti, Paolo (2007): "Direzione e coordinamento nei gruppi societari: principi e problemi”, Rivista delle società, Año 52, Vol. 2-3, marzo-junio: pp. 221-253.

Musso, Alberto (1996): La rilevanza esterna del socio nelle società de capitali (Milán, Giufrè).

Preite, Disiano (1992): "L'abuso" della regola di maggioranza nelle deliberazioni assembleari delle società per azioni (Milán, Giuffrè).

Perdices Huetos, Antonio (2002): "El concepto de administrador de hecho como criterio de imputación de la autoría en Derecho mercantil", en: Corcoy Bidasolo (coord.), Derecho penal de la empresa (Pamplona, Aranzadi) p. 134 y ss.

Pertínez Vílchez, Francisco (2009): "La responsabilidad concursal de los administradores sociales ex art. 172. 3 LC: una reflexión más sobre cuándo, cómo y quién”, en: Aranzadi Civil, $\mathrm{N}^{\circ}$ 5: pp. 2235-2270.

Pfeffer Urquiaga, Francisco (2001): "Nuevas regulaciones en las tomas de control y oferta pública de adquisición de acciones", Revista Chilena de Derecho, Vol. 28, N 1: pp. 113-141.

Prentice, Dan D. (1991): "Group Indebtedness in Schmitthoff C.M. / Wooldridge F". en: Groups of companies (Londres, Schmmitthof, Clive y Wooldridge, Frank, Sweet \& Maxwell) p. 55 y ss.

Puga Vial, Juan Esteban (2011): La Sociedad Anónima y otras sociedades por acciones en el derecho chileno y comparado (Santiago de Chile, Edit. Jurídica de Chile) .

Ríos Corbacho, José Manuel (2005): El Administrador de hecho en los delitos societarios (Cádiz, Edit. Universidad de Cádiz).

Roimiser De, Mónica G. C. (1979): El interés social en la sociedad anónima Buenos Aires, DePalma).

Rojas Miño, Irene y Aylwin Chiorrini, Andrés (2007): Los Grupos de Empresas en el Derecho Chileno del Trabajo (Santiago de Chile, LegalPublishing, segunda edición). 
Sánchez-Calero Guilarte, Juan (2002): "El interés social y los varios intereses presentes en la sociedad anónima cotizada”, Revista de Derecho Mercantil, N²46: p. 1653 y ss.

SÁnChez-Calero Guilarte, Juan (2005): "Algunas cuestiones concursales relativas a los grupos de sociedades", Anuario de Derecho concursal, N 5 (Madrid, Aranzadi) pp. 7-60.

SÁnchez Ruiz, Mercedes (2000): "Conflictos de intereses entre socios en sociedades de capital”, Revista de Derecho de Sociedades, Monografía, N 15, Navarra, Aranzadi: p. 45 y ss.

SERIK, Rolf (1958): Apariencia y realidad en las Sociedades Mercantiles. El abuso de derecho por medio de la persona jurídica (trad. José PUIG BRUTAU, Barcelona, Ariel).

TOMBARI, Umberto (2010): Diritto dei gruppi di imprese (Milán, Giuffrè).

Ulmer, Peter (1997): Gesellschaft bürgerlichen Rechts und Partnerschaftsgesellschaft ( München, Beck, tercera edición).

Vásquez Palma, María Fernanda (2013): Sociedades (Santiago de Chile, Thomson Reuters-LegalPublishing).

Vivante, Cesare (1935): "Società a catena e società finanziarie", Foro italiano, Vol. IV: p. 18 y ss.

Vivante, Cesare (1931): "La riforma delle società anonime: le società a catena", Rivista Bancaria, Vol. 2: pp. 150-155.

\section{OTRAS PUBLICACIONES}

"Comunicación de la Comisión al Consejo y al Parlamento Europeo. Modernización del Derecho de sociedades y mejora de la gobernanza empresarial en la Unión Europea - Un plan para avanzar", Bruselas, 21 de mayo de 2003, COM (2003) 284 final. Disponible en: http://eur-lex.europa.eu/LexUriServ/LexUriServ.do?uri=COM:2003:0284:FIN:ES:PDF.

"Corporate Group Law for Europe, Comments on the Forum Europaeum's Principles and Proposals for a European Corporate Group Law", en European Business Organization Law Review, 2000. Disponible en: http://windbichler.rewi.hu-berlin.de/EBORCorpGroupWindbichler.pdf.

KeYnes, John Maynard, "The End of Laissez-Faire?" en Essays in Persuasion. The Collected Writings of John Maynard Keynes, vol. IX, MacMillan Press, ed. de D.E. Moggridge y E. Johnson, Londres, 1984 (1926), pp. 282-284. Disponible en: http://www.panarchy.org/ keynes/laissezfaire.1926.html.

"Report of the High Level Group of Company Law Experts on a Modern Regulatory Framework for Company Law in Europe", Bruselas, 2004. Disponible en: http://ec.europa.eu/internal_market/company/docs/modern/report_en.pdf.

\section{JURISPRUDENCIA CITADA}

\section{SENTENCIAS CHILENAS}

CONADECUS con Lan Airlines S.A. y Tam Linhas Aéreas S.A. (2012): Corte Suprema, 5 de abril de 2012 (Reclamación D.L. 211), Rol N 9843-2011. Id. LegalPublishing $\mathrm{N}^{\circ} \mathrm{CL} /$ JUR/768/2012. 
Consorcio Allianz de Seguros Generales (actualmente AGF Allianz Compañia de Seguros Generales S.A.) con Sociedad Naviera Ultrajas Ltda.. y Ultramar Agencia Maritima Ltda." (2009): Corte Suprema, 2 de junio de 2009 (Acción de indemnización de perjuicios, juicio arbitral), Rol N 1527-2008. Id. LegalPublishing N CL/JUR/147/2009; 42232.

"Catrilef Hernández Salomón Neh con Pesca Cisne S.A" (2008): Corte Suprema, indemnización de perjuicios/responsabilidad extracontractual, Rol N²423-2008. Id. LegalPublishing $\mathrm{N}^{\circ} \mathrm{CL} / \mathrm{JUR} / 1676 / 2010$.

\section{SENTENCIAS EXTRANJERAS}

Comisión de las Comunidades Europeas (2008): Decisión de 16 de julio de 2008, relativa a la medida de ayuda ejecutada por Francia en favor del grupo IFP [C 51/05 (ex NN 84/05)], notificada con el número C (2008) 1330. Disponible en http://eur-lex.europa. eu/LexUriServ/LexUriServ.do?uri=OJ:L:2009:053:0013:0040:ES:PDF. Consultado el 26 de marzo de 2013.

Corte de Casación italiana (1976): Sentencia de 14 de julio de 1976, N³150, en "Rivista di diritto commerciale" (1978), II.

Corte de Casación italiana (1990): Sentencia de 26 de febrero de 1990, N¹439, en "Giurisprudenza commentata", 1991, II.

Tribunal Supremo español (2010): Sentencia de 25 de junio de 2010, Recurso de Casación núm. 519/2009, № Id. Aranzadi Westlaw RJ $2010 \backslash 7169$.

TS italiano (1972): Sala de lo Penal, de 29 de diciembre de 1972, en Giustizia penale, 1973 , II, p. 591.

Audiencia Provincial de Barcelona (1997): Sentencia de 11 de marzo de 1997, Recurso de Apelación, en "Revista General de Derecho", No 640-641, 1998, p. 1297 y ss.

Cour de Cassation (1985): Sentencia de 4 de febrero de 1985, en "Revue des Sociétés", Dalloz, 1985, p. 648 y ss. 